\title{
Practical recommendations for performing ultrasound scanning in the urological and andrological fields
}

\author{
Pasquale Martino ${ }^{1}$, Andrea Benedetto Galosi ${ }^{2}$, Marco Bitelli ${ }^{3}$, Paolo Consonni ${ }^{4}$, Fulvio Fiorini ${ }^{5}$, \\ Antonio Granata ${ }^{6}$, Roberta Gunelli ${ }^{7}$, Giovanni Liguori ${ }^{8}$, Silvano Palazzo ${ }^{1}$, Nicola Pavan ${ }^{8}$, \\ Vincenzo Scattoni ${ }^{9}$, Guido Virgili ${ }^{10}$, and Imaging Working Group - Società Italiana Urologia (SIU) \\ in collaboration with the Società Italiana Ecografia Urologica Andrologica Nefrologica (SIEUN)
}

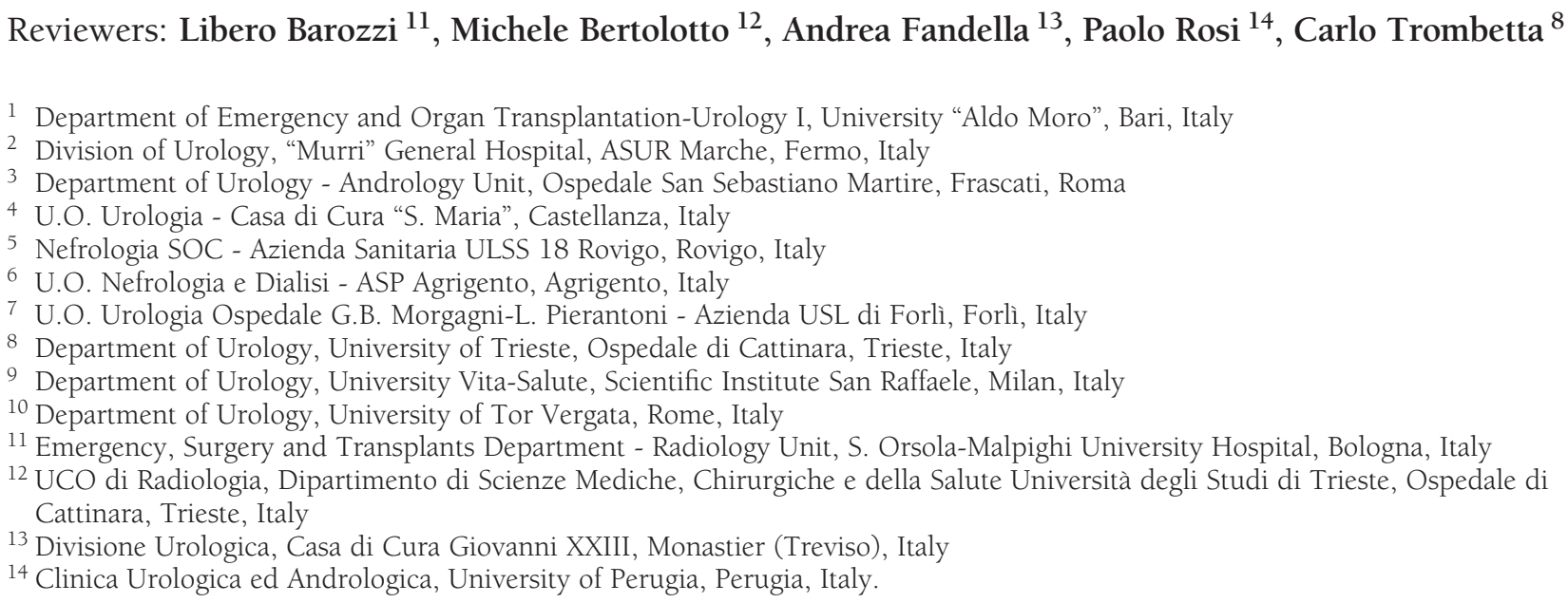

\begin{abstract}
Summary Aim: US scanning has been defined as the urologist's stethoscope.

These recommendations have been drawn up with the aim of ensuring minimum standards of excellence for ultrasound imaging in urological and andrological practice. A series of essential recommendations are made, to be followed during ultrasound investigations in kidney, prostate, bladder, scrotal and penile diseases.

Methods: Members of the Imaging Working Group of the Italian Society of Urology (SIU) in collaboration with the Italian Society of Ultrasound in Urology, Andrology and Nephrology (SIEUN) identified expert Urologists,

Andrologists, Nephrologists and Radiologists.

The recommendations are based on review of the literature, previously published recommendations, books and the opinions of the experts. The final document was reviewed by national experts, including members of the Italian Society of Radiology.

Results: Recommendations are listed in 5 chapters, focused on: kidney, bladder, prostate and seminal vesicles, scrotum and testis, penis, including penile echo-doppler. In each chapter clear definitions are made of: indications, technological standards of the devices, the method of performance of the investigation.
\end{abstract}

The findings to be reported are described and discussed, and examples of final reports for each organ are includ$e d$. In the tables, the ultrasound features of the principal male uro-genital diseases are summarized. Diagnostic accuracy and second level investigations are considered. Conclusions: Ultrasound is an integral part of the diagnosis and follow-up of diseases of the urinary system and male genitals in patients of all ages, in both the hospital and outpatient setting. These recommendations are dedicated to enhancing communication and evidence-based medicine in an inter- and multi-disciplinary approach. The ability to perform and interpret ultrasound imaging correctly has become an integral part of clinical practice in uro-andrology, but intra and inter-observer variability is a well known limitation.

These recommendations will help to improve reliability and reproducibility in uro-andrological ultrasound scanning.

KEY WORDS: Recommendation; Ultrasound scanning; Kidney; Bladder; Prostate; Scrotum; Penis.

History of the papers

Submitted 24 February 2014; Accepted 3 March 2014

No conflict of interest declared 


\section{Introduction}

These recommendations have been drawn up by the "Imaging" working group of the Società Italiana di Urologia (SIU) in collaboration with the Società Italiana di Ecografia Urologica Andrologica Nefrologica (SIEUN). The specialists involved in the work include Urologists, Andrologists, Nephrologists and Radiologists.

The aim of this work is to support Urologists in clinical practice, supplying a series of recommendations to be followed during the phases of ultrasound diagnosis of renal, prostatic, bladder, scrotal and penile diseases. These recommendations are based on a review of the literature, on previous recommendations and on the opinions of the experts (1-3).

This document is the first to be devoted to this sector, although the American Urological Association (AUA) and the American Institute of Ultrasound in Medicine (AIUM) recently (November 2011) published practical guidelines for the performance of ultrasound in the urological field [www.aium.org] (2). The references will serve to make a constructive comparison with other clinical experiences.

These recommendations were developed and drawn up with the aim of ensuring minimum standards of excellence for ultrasound imaging in urological practice, based on the assumption that ultrasound plays an essential part in this practice. Doctors specializing in Urology can gain particular skills and training in the use of ultrasound scanning during their residency years, in post-graduate dedicated courses organized by Universities, in training courses organized by urological scientific societies (SIU, SIA, EAU, AUA) and dedicated societies (ESUI, SIEUN), both nationally and internationally.

For the urologist, US scanning is an integral part of the processes of diagnosis and follow-up to manage diseases of the urinary tract and male genitals in patients of all ages, in both a hospital and an outpatient setting. The ability to perform and interpret imaging studies has become an integral part of clinical practice in all nations, also in order to optimize resources and provide patients with efficacious, rapid care. US scanning has been defined as the urologist's stethoscope. This also applies in the Andrological field.

Urologists must combine skilful use of sophisticated imaging devices with a deep knowledge of the physiological and pathological processes affecting the human body. If the diagnostic test will be performed in another Department they must be able to select the best test or series of tests to be made for the specific patient, to optimize the management of the urological patient.

These recommendations may be useful to ensure minimum shared or reference standards in the urological and andrological fields also for other medical specialists who perform urological US scanning, such as radiologists, internists, geriatricians, gynecologists or other doctors who study the urinary tract.

The aims of the present recommendations are:

- To define the purpose of each specific ultrasound investigation (to clarify what each investigation aims to discover).

- To define the indications.
- To establish the requisite technological standards of the devices.

- To outline the method of performance of the investigation.

- To establish the expected accuracy of the investigation in question.

- To indicate the reporting method.

Apart from their utility as a theoretical-practical tool for making a correct ultrasound examination of the genito-urinary apparatus, these recommendations we propose have the aim of guiding the Urologist in the assessment of the risks and benefits of diagnostic imaging so as to optimize the management of the urological patient ["Patient care is optimized when Urologists coordinate the use of imaging techniques and dedicated devices in the most advantageous place for their patients" - see (AUA, AIUM develop joint guidelines for urologic ultrasound exams)] (2). Below, brief recommendations regarding the equipment, documentation, reporting of the findings, training requirements and patient safety in ultrasound studies, are listed.

\section{EQUIPMENT}

Ultrasound scanning must be performed with devices that can provide images in real-time, thanks to the use of transducers that can optimize the penetration of the ultrasound waves inside the tissues, with excellent resolution obtained by setting appropriate frequency intervals.

The advised transducer frequencies are 3.0-5.0 $\mathrm{MHz}$ for abdominal scanning, 6.0-9 MHz for transrectal and 7.0$12.0 \mathrm{MHz}$ for genital scanning, while intraoperative renal or testicular scanning can be done with the transducer set at 6-10 MHz in linear mode. The correct setting of the device must also include the generation of good documentation of the investigations made.

\section{Documentation}

Each ultrasound investigation must be concluded with the production of appropriate, unequivocally clear images, recorded on a durable support (digital format is preferable) and saved in the patient's clinical files. The operator must check that the images are correctly recorded on the electronic support and readable in terms of contrast and luminosity.

The ultrasound images must also be labeled with the patient's personal data and those of the health care facility where the investigation is made (hospital department or outpatients clinic). The date and type of probe are automatically specified by the device.

\section{REPORTING OF FINDINGS}

Apart from acquiring full documentation of the investigation, complete reporting of the findings must be made, specifying any conditions during the execution phase that could affect the reliability or accuracy of the test (e.g. anatomical causes [bowel gas, malformations], causes depending on the patient [poor compliance, pain during 
the test], conduction in emergency regime, etc.). The report must include the name and signature of the doctor. Ultrasound scanning is performed for specific purposes and the simple production of images, even of good quality, can never replace a description of the clinical picture and the interpretation of the findings by the operator.

\section{TRAINING REQUIREMENTS}

Adequate training is an essential prerequisite for the correct performance and interpretation of ultrasound investigations. This training must be obtained both by residents at the specialist schools and by those who are already specialists in Urology. They should all undergo regular updating of their ultrasound scanning skills, the former during their specialist studies and the latter at regular periodical updating courses. The main scientific societies are active in organizing such updates, and issue certificates of attendance at such training and updating courses.

\section{Patient safety}

Ultrasound procedures must be performed only for the specific indications of the case, like any other imaging technique. In fact, like all specialists, urologists should comply with the principles of Alara (4), reducing to a minimum patients' exposure to acoustic energy (5). In addition, the operator must ensure that the ultrasound probe is clean and protected, to comply with the guidelines of the CDC (Centers for disease control and prevention) for the standards of disinfection and sterilization of the devices $(6,7)$, as well as the technical recommendations specified by the manufacturers of the various devices.

Regular periodical controls of the devices must be made, with the collaboration of the manufacturers and complying with the safety norms they list.

\section{Process of assessment of the Recommendations}

An assessment of the true effectiveness of these recommendations in modifying behavior and improving the clinical outcome will be made using control procedures that are currently being defined.

\section{UPDATING}

In the expectation of upcoming technological and/or diagnostic advances, the present recommendations will be integrated by further publications, likely every 3 years.

\section{Ultrasound scanning of the kidney}

\section{INTRODUCTION}

The kidneys are a pair of organs located at the retroperitoneal level: each kidney is situated along the lateral margin of the psoas muscle, that lines it posteriorly, while it is adjacent to the bowel anteriorly. The right kidney lies about 2-3 cm lower than the left. The kidneys have the function of purging the organism of a great number of substances, and also play a part in many metabolic pathways (protein, lipid and glucides), including the metabolism of hormones and vitamins, as well as control of the blood pressure. Healthy kidneys are easily assessed by ultrasound scanning because the parenchymal component is well delineated by the capsule and has a different echostructure from the perirenal fat and the pyelic structures.

\section{Measurements}

Measurements of the kidney length are made by scanning along the major axis parallel to the adjacent psoas muscle. The oblique plane of this long axis is measured by scanning the superior pole more medially and the inferior plane more laterally/anteriorly.

The angle between the long axis and the sagittal plane ranges between 8 and 10 degrees (1).

Variations in this angle produce the variability between ultrasound measurements of the length and measurements made with conventional radiology or urography (2). With ultrasound scanning it is easy to make reliable, repeatable real-time measurements of the kidney long axis.

It is clear that to make a precise measurement of the kidney axis it is necessary to identify the superior and inferior poles: this may be complex in cases of a malrotated, ectopic, ptosic, or scoliotic kidney, etc.

Measurement of the interpolar renal diameter is more accurate when the patient is placed in supine decubitus, slightly turned toward the contralateral side.

Oblique posterior longitudinal scanning is performed with the patient holding the homolateral arm above the head and breathing deeply, to shift the kidney under the ribs. Measurements in prone position tend to result in an underestimation of the kidney length, but may need to be done if the kidney is poorly visualized in other scans (3). In clinical practice ultrasound measurement of the kidney volume is not performed because it is difficult to do and highly error-prone, even if it can be useful to assess renal anomalies (4).

Renal volume can be assessed by measuring the 3 orthogonal diameters and applying the following formula:

$$
\text { volume } \mathrm{V}=0.49 \times \mathrm{L} \times \mathrm{W} \times \mathrm{AP}
$$

where $\mathrm{L}$ is the length of the major axis (longitudinal scan), W is the length measured at the renal hilum (transverse scan) and AP the anteroposterior diameter again measured at the hilum (transverse scan) (5). The photos on which the measurements were based should be stored in the documentation of the investigation.

It may soon be possible to make ultrasound measurements of the renal volume using 3D probes, that allow a greater precision than the common 2D probes (6).

In any case, correct measurement of the volume of the kidneys requires good operator skills and knowledge of the renal anatomy, consisting of three different components:

1) The hyperechogenic external capsule;

2) The hypo-isoechogenic parenchyma as compared to the echostructure of the liver and spleen, between the capsule and pelvis, consisting of 
a. the external echogenic cortex, being the functional portion

b. the internal hypoechogenic medulla, corresponding to the medullary pyramids with a triangular structure and the base toward the outside.

3) The kidney sinus, hyperechogenic due to the presence of many interfaces consisting of intrarenal adipose tissue.

\section{INDICATIONS}

Renal ultrasound scanning is indicated in the first approach to patients with renal disease and in the follow-up.

The investigations include:

- assessment of the kidneys, in normal or ectopic sites;

- assessment of the ultrasound morphology;

- diagnostic workup in patients with acute or chronic kidney disease;

- assessment of any dilation of the excretion pathways and differential diagnosis between obstructive and non obstructive acute renal failure (ARF);

- identification of space-occupying lesions (cysts and tumors);

- searching for stones;

- EchoColorDoppler assessment of the renal vascularization (both with color-powerDoppler and, in selected cases, contrast enhanced ultrasound [CEUS]) (11);

- assessment of the intrarenal resistance indexes (RI) at the level of the interlobar and/or arcuate arteries in nephropathic, hypertense, diabetic, nephroangiosclerotic patients;

- guidance of renal needle biopsy performed in the course of kidney disease or to exclude cancer;

- guidance of renal puncture in the course of hydronephrosis, abnormal cysts inducing symptoms;

- assessment of kidney transplant/s (just like the native kidney) and complications.

- intraoperative guidance in conservative kidney surgery, percutaneous lithotrypsy, non surgical ablation of expanding lesions;

- post-surgical monitoring or endourological treatments.

\section{Preparation for the investigation}

Although no specific preparation is considered strictly necessary, some suggestions are made with the aim of optimizing the performance of the investigation. It is better if the patient is asked to refrain from drinking fizzy drinks, fermented cheeses, vegetables, fruit and wholemeal foods, pulses. In cases of a "sluggish" bowel the patient should take a laxative the evening before. Since renal studies should always include a study of the bladder, this should be replete but not distended.

\section{SPECIFICATIONS OF THE MINIMUM REQUIREMENTS FOR THE ECHOGRAPH AND PROBES}

To study the kidney, a latest generation echograph, if necessary portable, should be used, of average range equipped with color-powerDoppler module and if possible, suitable software for contrast enhancement. Multifrequency convex probes allow study of the native and transplanted kidney, but for facilities that receive kidney transplant patients it is very useful to be able to employ a multifrequency linear probe. A thermal printer is indispensable, as is a magnetic image storing system. A recent generation US device offers pre-settings of the parameters to be assessed for each organ and probe, especially during echocolor-doppler investigations. These settings are defined during the installation but must be checked by the operator, updated or modified according to need and the characteristics of the tools available, as approved by the manufacturer.

\section{Parameter Assessed}

1. Position of each kidney, including malpositioning: unilateral agenesis, ptosic, malrotated, or dysmorphic kidney, (horseshoe, etc.);

2. KIdney size (7):

- maximum interpolar diameter (normal.: right $\mathrm{cm}$ $10.646 \pm 1.345$, left $\mathrm{cm} 10.130 \pm 1.165)$

- transverse diameter (normal.: right $\mathrm{cm} 4.920 \pm$ 0.638 , left $\mathrm{cm} 5.303 \pm 0.744)$

- parenchymal thickness (normal: $1.5-2.0 \mathrm{~cm}$ ) [measurement of cortical thickness is not always possible due to poor cortico-medullary differentiation, and suffers from high inter and intraobserver variability, so it is not commonly used] $(8,9)$;

3. Assessment of the kidney outline, that may feature the persistence of fetal lobes in the tract between two consecutive pyramids and/or the presence of grooves (scars after pyelonephritis) at one or more calyces;

4. Check for stones (hyperechogenic image measurable by posterior shadow cast);

5. Check for distension of the kidney ampulla and calyces (pyelic ectasia, calico-pyelic ectasia or hydronephrosis);

6. Check for distension of the ureter (hydroureteronephrosis);

7. Check for space-occupying lesions and differentiate between fluid (cysts) and solid lesions (neoplasia);

8. Assess renal vascularization using color and powerDoppler to identify "minus" signs (9);

9. Assess renal vascularization by contrast enhancement (CEUS), that improves diagnostic confidence in the assessment of deficiency signs (11);

10. Assess the intrarenal resistance indexes (RI): vn $<0.70$ (10) (optional, depending on the clinical picture).

\section{EXAMPLE OF REPORT KIDNEY ULTRASOUND}

Kidneys in situ, maximum longitudinal/transverse size within normal limits (right $\mathrm{cm} \_$__ l left $\mathrm{cm} \_$___ regular outlines. Parenchyma thickness normal $(\mathrm{mm})$. Regular echogenicity of parenchyma.

No direct or indirect signs of kidney stones.

Regular excretion pathways with no ectasia or calicopyelic dilation (or distinguish ectasic/ pyelic, calico-pyelic dilation, associated or not with ureteral dilation).

No space-occupying lesions. Adrenal loggia, no expanding lesions. 


\section{Renal Echo-Color-Doppler}

Intrarenal resistance indexes (interlobar or arcuate arteries) within normal limits $(R I<0.70)$

Systolic peak velocity (SPV) of the renal arteries at the ostium, initial, medial, distal and anterior and posterior segmentary tracts within normal limits. Flowmetry normal.

Pervious renal veins. At powerDoppler, good vascular appearance of parenchyma.

Minimum imaging documentation to be included:

1. Two images per kidney: transverse and longitudinal scans with measurements.

2. Orientation of images (liver/spleen on left).

3. Arrow on photo, indicating organ analyzed and side

4. Accessory images illustrating any anomalies.

5. If the bladder is described in the findings, at least one bladder scan image must be included.

\section{Ultrasound of the bladder}

\section{INDICATIONS}

- To measure post-voiding residue.

- To measure bladder filling volume.

- To assess anatomic modifications/complications associated with obstruction (diverticuli, trabeculation/columnar thickening, stones, detrusor thickness).

- To assess hypermobility of the bladder neck in women with stress incontinence.

- To assess hematuria originating in the lower urinary tract.

- To assess lower urinary tract symptoms - LUTS.

- To check for suspected ureteral stone migrating intramurally.

- To check for congenital malformations (ureterocele, diverticuli, etc.).

- Post-surgical monitoring (vesical bleeding, position of catheter, etc).

- Follow-up in non infiltrating cancer.

- Follow-up of bowel loop orthotopic bladder after cystectomy.

\section{Tools}

During standard investigations in the adult a Convex $3.5 \mathrm{MHz}$ probe (range $3-5.5 \mathrm{MHz}$ ) is used (in pediatric patients a higher frequency transducer can be used). To measure bladder volume in post voiding controls, automatic equipment can be used. In dynamic studies (e.g. assessment of cystocele) trans-rectal or trans-vaginal probes can be used. To stage bladder tumors trans-rectal probes can be used.

\section{TECHNIQUE}

Use adequate amounts of gel.

For optimal imaging of the bladder it should be full but not overdistended, especially in cases of obstruction.
The patient should be lying supine (supine or lithotomic or in orthostatic position in cases of use of a trans-rectal probe).

The bladder wall and lumen will be assessed during the investigation, with both transverse and sagittal scans (1). Systematic search and documentation must be made of: any changes in the echographic appearance of the bladder wall and neck at rest, trabeculature of the detrusor, endophytic neoplasia, diverticuli, stones, the presence of a third prostatic lobe.

Any focal lesions observed (in particular masses) and other diseases (diverticuli, stones, clots, etc.) must be described, specifying site and size.

When indicated, the distal ureters should be assessed to exclude dilation or other anomalies (intramural or juxtavesical stones, ureterocele).

Echo-Doppler study may be useful to assess ureteral jet and make a differential diagnosis of bladder tumors (2). Fine regulation of the light is essential to obtain a significantly improved image quality and correctly visualize the anterior wall (superficial as compared to the skin) and posterior wall (deep). Use the second tissue harmonic imaging tool to improve the imaging and reduce reverberation artefacts.

Calculate bladder volume:

$$
\text { (ellipsoid formula) } \mathrm{v}=0.52 \times \mathrm{r} 1 \times \mathrm{r} 2 \times \mathrm{r} 3 \text {. }
$$

It is recommendend to assess post-voiding urine residue by ultrasound using automatic measurement tools or using the ellipsoid formula based on bladder diameters. In cases of a significant post voiding residue the patient should be asked to make a further attempt to void and then the measurements repeated until a reliable indication of the voiding capacity is obtained.

In cases of assessment of the detrusor thickness (not normally more than $3 \mathrm{~mm}$ ) the study will be conducted with moderate bladder filling (calculated as between 250 and $350 \mathrm{ml}$, with $250 \mathrm{ml}$ as threshold value), the mean of 3 measurements made on the same image is calculated. To obtain the best results the assessment must be made at the level of the anterior wall/apex and it is better if a high frequency $(7.5 \mathrm{MHz}$ ) convex or linear probe is employed (1). The ultrasound appearance of the detrusor is as a sandwich structure (hypoechogenic muscular wall between the mucosa and adventitial layers, that are slightly hyperechogenic).

The detrusor thickness must always be measured in areas that are orthogonal to the ultrasound focus (3-8).

The findings report should include:

- The patient's name and surname;

- The name of the Service where the investigation was performed and the telephone number (in case further clarification should be required);

- The date of the ultrasound examination;

- If possible include all pertinent clinical information, including the indications for the investigation;

- The type of ultrasound examination performed, and if endocavitary techniques are employed the method must be specified; 
- Specify the orientation of the image, if different from standard (superior part on the right of the screen);

- Use appropriate anatomical and ultrasound terminology; in cases of variations from normal sizes the measurements must be specified (e.g. increased detrusor thickness, diverticuli, endoluminal masses, etc.);

- Compare with previous imaging studies if available; suggest types of studies for further investigation, any differential diagnosis hypotheses;

- Name and signature of the examiner, date;

- If the results of the ultrasound are considered by the doctor performing the investigation to be of particular clinical importance and unexpected, such as to require urgent intervention to guarantee proper patient care, ideally the doctor who did the investigation should contact the patient's doctor directly to check that the findings report has been received;

- Describe the state of other organs in the abdomen only if qualified to do so;

- Pay attention to the degree of distension of the bladder, that can negatively affect the visualization of the ureters in the juxtavesical tract, and the seminal vesicles;

- Use the tissue harmonic imaging tool to reduce reverberation artifacts and obtain better detail;

- Indicate any difficulties encountered while performing the investigation (patient's collaboration and constitution, presence of bowel gas), underlining any limits of the test and so its diagnostic value.

\section{EXAMPLE OF FINAL REPORT}

1. Presence or absence of bladder.

2. Orthotopic site and symmetry.

3. Shape.

4. Degree of bladder distension (essential for reliability of investigation).

5. Presence or absence of wall alterations (assessment of lesions $>3 \mathrm{~mm}$ )

6. Presence or absence of third lobe (in cases where present, volume and/or degree of extension into the bladder: Intravesical prostatic protrusion).

7. Presence and size of calcifications (diameter $>3 \mathrm{~mm}$ ), fixed or mobile with patient's movements in decubitus.

8. Characteristics of bladder neck (in man, protrusion of prostate).

9. Presence of the ureters and any dilation or abnormal outlet or stones.

10. Presence of pelvic masses and ab-extrinseco compression of the bladder.

11. Quantification of post voiding residue.

Note:

It is necessary to calculate the bladder filling volume only if needed to measure the detrusor thickness or estimate the bladder weight (reliable for values $\geq 250 \mathrm{ml}$ ) or if needed for clinical reasons. Describe any clinical conditions that prevent adequate bladder filling (incontinence, pain due to reduced compliance).
Images to be included (not all are always indispensable, depending on the clinical picture)

1. One image of the bladder in transverse scan.

2. One image of the bladder in longitudinal scan

3. One image of the bladder in transverse/longitudinal scan showing the bladder neck.

4. One or more images of any anomaly.

5. In cases of a lesion obstructing the juxtavesical ureter (stone or vegetating lesion) oblique scanning must be done.

\section{Preparation for investigation AND PATIENT POSITION}

1. The patient does not need to be fasting.

2. The bladder must be replete with at least $300 \mathrm{cc}$; to ensure this it is necessary:

a. for the patient to drink at least $500 \mathrm{cc}$ of fluids during the three hours before the investigation;

b. for the patient to refrain from urinating within two hours before the investigation;

c. for the patient to feel the urge to urinate (this latter parameter is extremely subjective and not always reliable).

The investigation is normally performed with the patient in supine position. Lateral right or left decubitus may rarely be necessary, in cases where a lesion extends into the lumen (neoplastic disease, clots, "intravescical prostatic protrusion") and its mobility must be checked. In cases requiring oblique scanning, this is done by rotating the probe by about $40^{\circ}$ to its longitudinal axis, taking care that the bladder filling is not more than 250-300 cc (otherwise the ureters would appear crushed by the bladder volume itself).

\section{US PAREMETERS TO EVALUATE BLADDER MODIFICATIONS IN PATIENTS WITH BLADDER OUTLET OBSTRUCTION}

Progressive changes in the bladder wall are observed in men with lower urinary tract obstruction secondary to benign prostatic enlargement (BPE).

The high pressure discharge cause initially an increase in the proportion of smooth muscle (hyperplasia/hypertrophy of the detrusor) to changes in the advanced stages of bladder decompensation (fibrosis), hyperactivity and decreased functional capacity. Early identification of bladder changes by noninvasive transabdominal ultrasound can move towards therapeutic choices that can prevent further organ damage in the bladder wall. Measurement of the Bladder Wall Thickness (BWT) or Detrusor Wall Thickness (DWT) by US is reliable, at least 3 measurements of the anterior bladder wall taken at a filling volume of $\geq 250 \mathrm{ml}$. In particular, the DWT [thickness of the muscle hypoechoic between two layers hyperechoic serosa and mucosa] is considered the best diagnostic tool to measure detrusor hypertrophy using cut-off value $>2.9 \mathrm{~mm}$ in men. US derived measurements of bladder weight (Estimated Bladder Weight, EBW) is another noninvasive tool for assessing bladder modifications in patients with Bladder Outlet Obstruction (BOO): cut-off value 35 gr. Technique for measuring the BWT and 
EBW relies in conventional US 7.5-4 $\mathrm{MHz}$ or using the automatic system of calculation (BVM $65003.7 \mathrm{MHz}$ ).

The variability of measuring intra (4.6 to $5.1 \%$ ) and interoperator (12.3\%) is acceptable. Also conventional US detects established signs of bladder damage: diverticulosis, trabecolations in the bladder wall (pseudo-diverticula), calculi and post-void residual urine $(>50 \mathrm{cc}$ ). Furthermore the Intravescical Prostate Protrusion (IPP), easy measured by transabdominal ultrasound, is strongly correlated to obstruction in men with BPE (cut-off $12 \mathrm{~mm}$ ).

Measure, quantify and monitor the cervico-urethral obstruction in men with symptomatic BPE is possible by non-invasively US monitoring the response of the bladder wall. Early identification has the advantage of adopting therapeutic measures sufficient to prevent progression of bladder damage measuring DWT, EBW in addition to established US paremeters (3, 5-10).

\section{Diagnostic accuracy}

In the diagnosis and follow-up of bladder tumors or hematuria, it should be noted that the standard method is uretero-cystoscopy.

Ultrasound scanning is an alternative for non invasive low grade tumors and for the initial assessment of hematuria. Cystoscopy allows the operator to assess and solve any doubts about the integrity and regularity of the bladder wall raised at ultrasound scanning. Bladder lesions smaller than $5 \mathrm{~mm}$ may not be identified at ultrasound. Not all bladder tumors are observed at ultrasound: slow-growing non vegetative tumors like carcinoma in situ are not diagnosed by imaging.

The diagnostic capacity for vegetating/papillary lesions $>5$ $\mathrm{mm}$ is high, even if in some circumstances differential diagnosis with clots may be difficult despite echocolordoppler.

\section{Non neoplastic diseases}

\begin{tabular}{|c|c|c|}
\hline & Parameter & Pattern \\
\hline Acute cystitis & Wall thickness and echogenicity. & $\begin{array}{l}\text { Increased hypoechogenicity, increased thickness of bladder wall, } \\
\text { between the serosa and mucosa. }\end{array}$ \\
\hline Chronic cystitis & & $\begin{array}{l}\text { No characteristic pattern, assessment of post-micturition residue, } \\
\text { search for foreign bodies in bladder. }\end{array}$ \\
\hline Bullous cystitis & Wall thickness, echogenicity. & $\begin{array}{l}\text { Increased bladder wall thickness, anechogenic areas } \\
\text { Wall hypoechogenicity. }\end{array}$ \\
\hline Diverticuli & Presence/absence. & $\begin{array}{l}\text { Formation of anechogenic paravesical areas with the presence of asonic } \\
\text { funnelling to bladder (diverticular neck): Transrectal scanning can better } \\
\text { reveal the diverticular neck. } \\
\text { Color-doppler can enable DD between tumors and endodiverticular clots, } \\
\text { although it is not the ultimate test. } \\
\text { In doubtful cases CEUS or other radiological or endourological imaging } \\
\text { should be done. }\end{array}$ \\
\hline $\begin{array}{l}\text { Detrusor hypertrophy } \\
(5-7,9)\end{array}$ & $\begin{array}{l}\text { Thickness detrusor wall (calculated } \\
\text { at } \geq 250 \text { ml of filling, as mean of } 3 \\
\text { measurements, hypoechogenic tissue } \\
\text { included between two lines of } \\
\text { hyperechogenic tissue: mucosa } \\
\text { and bladder serosa). }\end{array}$ & $\begin{array}{l}\text { Increased (> } 3 \mathrm{~mm} \text { ) with irregularities (trabeculatures or even pseudo } \\
\text { diverticuli). } \\
\text { Low Level Evidence, recommendations need to be verified on vast scale, } \\
\text { evidence levels based on opinions of experts and case series. } \\
\text { Parameter to be assessed, advised by experts. For use in clinical studies. }\end{array}$ \\
\hline Ureterocele & & $\begin{array}{l}\text { Anechogenic formation (cyst) at the level of the ureteral meatus with } \\
\text { evidence at color-doppler of ureteral jet. }\end{array}$ \\
\hline $\begin{array}{l}\text { Juxtavesical } \\
\text { Ureter lesion }\end{array}$ & $\begin{array}{l}\text { Juxtavesical ureter obstructive lesion } \\
\text { (stone or vegetating lesion). }\end{array}$ & $\begin{array}{l}\text { Hyperechogenic image with posterior shadow included in the thickness } \\
\text { of the ureteral wall (between hyperechogenic serosa). } \\
\text { Eco-color-doppler: useful to identify color signals (artifacts) in the shadow } \\
\text { area and in DD of vegetating lesions also with eco-power-doppler. } \\
\text { Evidence or not of Urethral Jet at color-doppler. }\end{array}$ \\
\hline Stones & & $\begin{array}{l}\text { Hyperechogenic images with shadow, mobile depending on decubitus } \\
\text { movements. }\end{array}$ \\
\hline $\begin{array}{l}\text { Hyperactive bladder } \\
(5,10)\end{array}$ & $\begin{array}{l}\text { Bladder weight (UEBW-ultrasound- } \\
\text { estimated bladder weight). }\end{array}$ & $\begin{array}{l}\text { No consensus in literature as to standardized cut-off values to be used } \\
\text { in clinical studies. }\end{array}$ \\
\hline
\end{tabular}

\section{Neoplastic diseases}

Although staging is not currently approved on the basis of the ultrasound findings, we report indications for a possible interpretation.

\begin{tabular}{|l|l|l|}
\hline Superficial lesions & Parameter & Pattern \\
\hline Infiltrating lesions & Bladder wall structure & $\begin{array}{l}\text { Generally no echostructural alterations of the wall. } \\
\text { Endophytic tumors appear as hypoechogenic, fixed proliferative lesions, } \\
\text { but sometimes they are hyperechogenic due to the presence of superficial } \\
\text { calcifications. At color-Doppler hypervascularization is observed. }\end{array}$ \\
\hline
\end{tabular}


Ultrasound of the pelvic floor $(4,11-24)$

\begin{tabular}{l|c|c|c|c|}
\hline & Trans-perineal & Introital & Trans-vaginal & Trans-rectal \\
\hline Instruments & $\begin{array}{c}\text { Convex } \\
3.5-5 \mathrm{Mhz} \text { probe }\end{array}$ & $\begin{array}{c}\text { Sector endfire } \\
5-7.5 \mathrm{Mhz} \text { probe }\end{array}$ & $\begin{array}{c}\text { Linear biplanar } \\
7.5 \mathrm{Mhz} \text { probe }\end{array}$ & $\begin{array}{c}\text { Linear biplanar } \\
7.5 \mathrm{Mhz} \text { probe }\end{array}$ \\
\hline Patient position & + lithotomic & lithotomic orthostatic & lithotomic orthostatic \\
\hline Quality of image & + & + & +++ & +++ \\
\hline Measurement of mobility & ++ & ++ & ++ & ++ \\
\hline Invasiveness & ++ & ++ & +++ \\
\hline Artifacts in 3-4 grade cystocele & ++ & + & + \\
\hline
\end{tabular}

Addendum: Possible use of 3D studies, especially for post surgical assessment (sling). Clinical studies to assess the presence of funneling of the neck, hypermobility of the neck-urethra complex, cystocele, ureteral fixity. No standards have yet been established for mobility parameters (among proposals see Schaer et al. Int Urogynecol J Pelvic Floor Dysfunc 1996, Pajoncini C. in Atlante di ecografia uro nefrologica ed andrologica 1996 ed. CIC, Merz et al. Ultraschall Med 2004, Tunn R. et al. Update recommendations on ultrasonography in urogynecology. Int Urogynecol J 2005 16, 236-241).

\section{Prostate and seminal vesicles}

\section{Prostatic UltRasound sCANNING WITH THE SUPRAPUBIC TECHNIQUE}

\section{Method}

The prostate must be analyzed on two orthogonal planes: transverse and longitudinal. In this study it is essential to examine:

- Juxtavesical ureters.

- Bladder.

- Prostate.

- Seminal vesicles (1-6).

The prostate diameters to be assessed are: latero-lateral, antero-posterior and cranio caudal.

In cases of an obstructive lesion of the juxtavesical ureter (stone or vegetating lesion) oblique scans must be made.

Images to be included (not all are always indispensable, depending on the clinical picture).

1. One image of the bladder in longitudinal/transverse scan.

2. One image of the prostate in transverse scan showing the bladder.

3. One image of the prostate in longitudinal scan showing the bladder.

4. One image of the right juxtavesical ureter in oblique scan.

5. One image of the left juxtavesical ureter in oblique scan.

6. One or more images of any anomalies.

\section{Report of the findings}

1. Date and place of performance of the investigation.

2. Patient data (including birth date).

3. Mention of clinical history and diagnostic purpose.
4. Value of last total PSA blood test.

5. Comparison with previous tests if available.

Both the images and findings must be easy to read by other operators and at later dates.

The findings must therefore be reported as unambiguously as possible. In cases of any diagnostic doubt, this must be pointed out, indicating possible hypotheses and suggesting any further instrumental investigations that may help to solve any doubts.

\section{TERMINOLOGY}

1. Identification of the medial lobe and its size and relations with the pelvic floor

2. Any picture of cervico-ureteral obstruction due to prostatic hypertrophy causing severe detrusor impairment, any presence of bladder stones (Table $\mathbf{1}$ ).

\section{INDICATIONS}

1. To assess the size and volume of the prostate gland before medical, surgical or radiation treatment (in particular, to assess the volume displacement caused by the third lobe and correlations with detrusor hypertrophy, the presence of bladder pseudodiverticuli and diverticuli $(1,6)$.

2. To assess the patient with Lower Urinary Tract Symptoms (1).

3. To assess congenital anomalies.

\section{ESSENTIAL PARAMETERS TO BE SPECIFIED IN THE FINAL REPORT}

\section{Prostate}

1. Presence or absence of the prostate.

2. Orthotopic or heterotopic site.

3. Shape.

4. Size. 
5. Presence or absence of third lobe (if present, volume and/or size of protrusion into the bladder: Intravesical prostatic protrusion).

6. Presence and size of any gross calcifications (diameter $>5 \mathrm{~mm}$ )

7. Presence and size of any gross abscesses/cysts (diameter $>5 \mathrm{~mm}$ ).

8. Presence of the ureters and any dilation or anomalous outlet.

9. Quantification of post voiding residue.

Note:

Lesions of any nature with a diameter of $\leq 5 \mathrm{~mm}$ are not identifiable with suprapubic ultrasound scanning. The suprapubic technique cannot visualize the echostructure of the peripheral zone of the prostate due to technical image resolution limitations.

\section{Seminal vesicles}

1. Presence or absence.

2. Site.

3. Symmetry.

\section{Bladder}

An accurate description of the bladder is essential, see previous chapter.

\section{Preparation for investigation and patient position}

1. The patient does not need to be fasting

2. The bladder must be replete with at least $300 \mathrm{cc}$; to ensure this it is necessary:

a. for the patient to drink at least $500 \mathrm{cc}$ of fluids during the three hours before the investigation;

b. for the patient to refrain from urinating within two hours before the investigation;

c. for the patient to feel the urge to urinate (this latter parameter is extremely subjective and not always reliable).

The investigation is normally performed with the patient in supine position.

Lateral right or left decubitus may rarely be necessary, in cases where a lesion extends into the lumen and its mobility must be checked.

\section{EXAMPLE OF Final REPORT}

Mention of clinical history:

Diagnostic purpose

Last total PSA value:

The bladder...

Yes/No Hyperechogenic bladder images depicting stones, nor dilation of the juxtavesical and intramural bilateral ureters.

The prostate is shown in orthotopic/heterotopic site and is grossly triangular, size within normal limits (morelless),

(LL X AP X CC), having a theoretical calculated volume of about $\quad m l$.

Presence of third lobe protruding into the bladder by _ $\mathrm{cm}$.

Post voiding residue is about cc.

Non/mild/fair/marked tenderness or pain on palpation of the hypogastrium at the start/throughout the duration of the investigation.

\section{Diagnostic ACCURACY}

It is important to note that the elective method for the study of the prostate gland includes the use of endocavitary probes $(7,8)$. In fact, suprapubic ultrasound scanning is not contemplated in the guidelines for the study of the prostate drawn up by the main scientific societies due to its limited diagnostic power (2-5).

In particular, it is thought that prostate ultrasound results in an overestimation by more than $30 \%$ to $50 \%$ of the true prostate volume. According to some Authors, moreover, the use of the ellipsoid formula to calculate the prostate gland volume with the aid of suprapubic ultrasound leads to an error of about 20\% (9).

\section{NOTES ON CLINICAL PRACTICE}

A. Attention must be paid to the degree of distension of the bladder, that can affect the visualization of the juxtavesical ureters and seminal vesicles

B. Use the tissue harmonic imaging tool to reduce reverberation artifacts and obtain better detail

C. Indicate any difficulties encountered while performing the investigation (patient's collaboration and constitution, presence of bowel gas), underlining any limits of the test and so its diagnostic value.

D. Remember that if the prostate is larger than normal, its morphology may vary, especially in cases of prostatic hyperplasia.

\section{DEVICES AND TRANSDUCERS USED}

Convex transducer with a frequency of $3.5 \mathrm{MHz}$, or multifrequency 5-2 $\mathrm{MHz}$ probes depending on the patient's constitution and how deeply the gland is located.

\section{TRANSRECTAL PROSTATIC ULTRASOUND}

\section{Method}

The investigation is dynamic and apart from longitudinal and transverse scans, with the probe inclined more craniocaudally than for the study of the bladder, oblique scans will also be performed to study the seminal vesicles, that generally lie on the transverse/oblique plane. The prostate must be analyzed on two orthogonal planes: transverse and longitudinal, from the apex to the base of the gland.

At the same time, it is essential to study:

- the urethra sphincter, Cowper's glands;

- the seminal vesicles;

- the juxtavesical tract of the ureters;

- the deferens ducts;

- the bladder (insofar as it is explorable).

Additionally, any gross alterations of the rectal wall should be pointed out, and referred to the competent specialist colleague. 
The diameters to be assessed is latero-lateral, antero-posterior and cranio-caudal, to calculate the total volume, and also the volume of the transition zone (periureteral hypertrophy). For the seminal vesicles the diameters assessed are: antero-posterior.

The apparent size of the latter may be affected by the degree of distension of the bladder, by ejaculation and by forms of obstruction (1-4).

Images to be included (not all are always indispensable, depending on the clinical picture)

1. One image of the prostate in transverse scan (indicating the diameters of both the entire gland and adenoma).

2. One image of the prostate in longitudinal scan (indicating the diameters of both the entire gland and adenoma).

3. One image of the prostate in transverse scan showing the bladder.

4. One image of the prostate in longitudinal scan showing the bladder.

5. One image of the seminal vesicles in transverse scan.

6. One or more images of any anomalies.

7. Any images of the juxtavesical ureter in longitudinal scan.

\section{Calculate total prostatic volume}

and transition zone volume

It is important to note that all latest generation ultrasound devices automatically calculate the volume of the prostate, bladder and seminal vesicles. If this is not possible, multiply the 3 diameters by 0.52 according to the ellipsoid formula. Data on the volume of the entire gland and adenoma are clinically essential for therapeutic and surgical workup purposes (5-11).

\section{Orientation of the ultrasound images}

The ultrasound probe always appears at the bottom of the image. In transverse scans: the patient's right side is conventionally on the left side of the image (as also in CT and MR images).

In longitudinal scans: the superior/proximal part/patient's head is conventionally on the left side (as in abdominal ultrasound imaging), and the distal part on the right side.

\section{Documenting the findings}

1. Date and place where the investigation was performed.

2. Patient data (including birth date).

3. Mention of clinical history and diagnostic query.

4. Value of last total PSA blood test.

5. Outcome of rectal exploration, that should always be done before the investigation.

6. Comparison with previous examinations, if available.

Both the images and findings must be easy to read by other operators and at later dates.

The findings must therefore be reported as unambiguously as possible.

In cases of any diagnostic doubt, this must be pointed out, indicating possible hypotheses and suggesting any further instrumental investigations that may help to solve any doubts.

\section{TERMINOLOGY}

1. Hypoechogenic pars adenomatosa, as compared to pars peripherica of the prostate $(6,8)$.

2. Identification of medial lobe, and its size and relationships with the bladder floor (5).

3. Presence of calcifications (diameter $\geq 3 \mathrm{~mm}$ ), that appear hyperechogenic with a posterior shadow (possibly showing signs of previous inflammation).

4. Presence of focal hyperechogenic areas with no posterior shadow (diameter $\geq 3 \mathrm{~mm}$ ) (possibly showing signs of previous inflammation).

5. Presence of abscesses and/or hypo/anechogenic areas (diameter $\geq 3 \mathrm{~mm}$ ), that appear prevalently with a fluid anechogenic or dyshomogenenous component, possibly showing inflammation processes in active phase. Anechogenic/echogenic areas of inflamed abscesses Table 2 .

6. In a picture of cervico-ureteral obstruction due to prostatic hypertrophy causing severe detrusor impairment, any presence of bladder stones Table 1 .

7. Dilation/cysts of the ejaculatory ducts.

8. Perviousness and funneling of the cervical or anastomotic region in surgical scars.

\section{INDICATIONS}

1. To assess the size and volume of the gland for medical/surgical workup, regardless of the type of treatment or underlying disease (1-14).

2. Prostatic biopsy guidance.

4. Suspected prostatitis and/or prostatic abscess.

5. To examine congenital anomalies.

6. In infertility of the couple (morphological study of the seminal tracts).

7. Study of the bladder neck

- Functional diseases of the bladder neck (sclerosis, iatrogenic stenosis or ndd);

- Neurological bladder;

- Outcome of surgery of the cervico-prostatic region (prostatic trans-vesical adenomectomy, endoscopic resection or enucleation of prostatic adenoma, endoscopic incision of bladder neck);

- Identification and examination of cysts of bladder neck or third prostatic lobe;

8. Postoperative controls (post disobstructive surgery or radical prostatectomy).

9. Post-treatment controls for prostatic tumors (radiotherapy, HIFU, cryotherapy) (8).

\section{ESSENTIAL PARAMETERS THAT MUST BE SPECIFIED IN FINAL REPORT}

\section{For all types of report}

Preliminarily, transrectal exploration must be performed, indicating the presence, size (x 2-3), surface, consisten- 
cy, margins, presence or absence of a medial groove, any nodules, their characteristics and localization), tenderness or pain on palpation of the gland.

\section{Prostate}

1. Presence or absence of the prostate.

2. Orthotopic or heterotopic site.

3. Symmetry.

4. Size/volume of the gland (latero-lateral, antero-posterior and cranio-caudal, to be multiplied by 0.52 , according to the ellipsoid formula, if the device does not make an automatic calculation).

5. Size/volume of the transition zone/adenoma.

6. Presence or absence of third lobe (if present, volume and/or measurements of protrusion into the bladder) $(5,16)$.

7. Presence and size of calcifications (diameter $\geq 3 \mathrm{~mm}$ ) Table 1

8. Presence and size of abscesses/cysts (diameter $\geq 3$ mm) (17).

9. Presence and size of intra-prostatic cysts or bladder neck cysts (diameter $\geq 3 \mathrm{~mm}$ ) (17).

10. Echostructure of the peripheral portion (18).

11. Integrity of prostatic capsule.

12. Presence of the ureters and any dilation or anomalous outlet.

13. Any pain elicited during the investigation Table 2.

\section{ADDENDUM IN PARTICULAR CASES}

Presence of the deferens and any dilation.

\section{URETHRA}

Any lesions evident at ultrasound.

Morphology and function of the internal urethral sphincter (only in cases of ultrasound performed for functional purposes)

\section{SEMINAL VESICLES}

1. Presence or absence.

2. Site.

3. Symmetry.

4. Morphology.

5. Any dilation (> $12 \mathrm{~mm}$ in antero-posterior site).

\section{BLADDER}

1. Morphology of walls.

2. Morphology of content.

3. Presence of vegetation and description.

4. Presence of stones.

\section{A. Prostatic biopsy guidance}

1. In cases of suspected tumor areas, describe:

- site;

- size;

- morphology;

- ultrasound appearance;

- margins

- relations of lesion with the capsule, bladder neck, seminal vesicles in cases of basal nodules with extracapsular extension.
If several nodules are present, each must be detailed as described above (19-20).

2. In cases of multiple prostatic biopsy sampling, indicate:

- type of patient preparation;

- antibiotic prophylaxis administered*;

- results of preliminary rectal exploration (and any agreement between increased consistency areas at palpation and suspicious ultrasound images);

- type of anesthesia (site, drug and dosage);

- number of samples, specifying scheme adopted

- course of procedure

- indications for patient care in days after the manoeuvre;

- any home antibiotic therapy*.

\footnotetext{
* Antibiotic prophylaxis has proven useful for the prevention of complications such as asymptomatic bacteriuria, urinary tract infections, bacteremia and sepsis (1).

The fluoroquinolones (such as ciprofloxacin XR $1000 \mathrm{mg}$ ), due to a better prostatic penetration, allow maintenance of constant levels of antibiotic in tissue, thus ensuring optimum prophylactic efficacy (2).

\section{REFERENCES}

1. Zani EL, Clark OA, Rodrigues Netto N Jr. Antibiotic prophylaxis for transrectal prostate biopsy. Cochrane Database Syst Rev. 2011; (5):CD006576.

2. Grabe M (chairman), Bjerklund-Johansen TE, Botto H, et al. Guidelines on Urological Infections. European Association of Urology 2013.
}

\section{B. ASSESSMENT OF CONGENITAL ANOMALIES}

In particular, apart from studying alterations of the course of the juxtavesical ureters, transrectal prostatic ultrasound is able to demonstrate intraprostatic cysts. Cystic lesions appear as round or oval, with distinct margins and an asonic content.

The definition of the site is particularly important, namely: 1. Vesical.

2. Medial posterior: mullerian/prostatic utricle.

3. Paramedial/lateral: ductal dilatation/cysts of ejaculatory duct.

4. Due to retention (17)

\section{MORPHOLOGIC STUDY OF THE SEMINAL TRACT}

\section{EJACULATORY DUCTS}

1. Presence or absence.

2. Presence or absence of calcifications and any obstruction caused.

3. Any dilation.

DEFERENS DUCTS

1. Presence or absence.

2. Presence or absence of calcifications or lesions and any obstruction caused

3. Any dilation.

SEMINAL VESICLES

1. Diameters (latero-lateral, antero-posterior and craniocaudal).

2. Any dilation

3. Any congestion.

4. Anomalies with the deferens. 


\section{STUDY OF THE BLADDER NECK}

1. Morphology (5).

2. Symmetry.

3. Any calcifications.

4. Any cysts (17).

\section{E. STUDY OF THE PROSTATIC LOGGIA AFTER RADICAL PROSTATECTOMY OR OTHER TREATMENTS}

Presence of areas suggesting disease recurrence in the perianastomotic region:

- site;

- size;

- localization with respect to the anastomotic region and rectal wall;

- ultrasound appearance;

- margins;

- vascularization;

- presence/absence of seminal vesicles residues.

The ultrasound data must necessarily be correlated with the total PSA values and clinical history, because subsequent treatments for postoperative urinary incontinence may modify the echostructure and mimic lesions (macroplastique, collagen, bulkamid).

If biopsy samples are taken of the perianastomotic region, all suspicious areas should be sampled; this can be done under ultrasound guidance (15).

\section{Preparation for the investigation AND PATIENT POSITION}

The patient must undergo at least one enema two hours before the investigation, to avoid artifacts caused by fecal matter in the rectum.

Fasting is not necessary.

The patient must not urinate for at least two hours before the investigation (the bladder must be replete).

The investigation is normally performed with the patient in lateral left decubitus. If this is impossible, it can be done in lateral right decubitus or semilithotomic position.

\section{EXAMPLE OF FinAL REPORT}

\section{Standard transrectal prostatic ultrasound}

Mention of clinical history:

Last total PSA value:

Preliminary rectal exploration shows the prostate in situ, enlarged (X), with a smooth surface, parenchymatous consistency, distinct margins, flattened medial groove.

No tenderness or pain on palpation.

The prostate, investigated with a transrectal "end-fire" ultrasound probe with variable frequency, is visible in situ and roughly triangular in shape; the size is $X X \mathrm{~mm}$ (LL X AP X CC), for a theoretical calculated volume of about cc. A central nodular area of hyperplasia is present, with a dyshomogeneous echostructure, and theoretical calculated volume of about cc.

Along the cleavage plane of the nodular hyperplasia, and in the periureteral site, calcifications are evident, likely the outcome of previous inflammatory processes.

Within the nodular hyperplasia area there are gross calcifications as well as some anechogenic images compatible with cysts due to retention/microabscesses.

The peripheral gland shows a substantially homogeneous structure, with no signs of disease foci in course.

The seminal vesicles are orthotopic and normal in shape.

The bladder is in situ, moderately distended.

No ultrasound alterations of the posterior bladder

wall are apparent, insofar as the area is visible

through the transrectal acoustic window.

Post-voiding urinary residue is ...

\section{Transrectal prostatic ultrasound to study}

the seminal vesicles

The prostate is described as above.

No evidence of obstructive lesions of the ejaculatory ducts and deferens ducts bilaterally.

The seminal vesicles are orthotopic and normal in shape. The maximum diameters of the right seminal vesicles are $X X X \mathrm{~mm}$ (CC X AP X LL), for a theoretical calculated volume of about cc. The maximum diameters of the left seminal vesicle are $X X X \mathrm{~mm}$ (CC X AP X LL), for a theoretical calculated volume of about $C C$.

Post-voiding urinary residue is $c c$.

Deferens present, symmetrical and not dilated.

\section{Prostatic ultrasound of the perianastomotic region after prostatectomy}

The perianastomotic region appears

homogeneous/dyshomogeneous, showing areas of .. in size, localized at the level of .., with ...margins, vascularized, suspicious for growth processes.

\section{Diagnostic accuracy}

The diagnostic accuracy of transrectal prostatic ultrasound varies according to the diagnostic query.

In particular, as regards assessing the size of the prostatic adenoma, the diagnostic accuracy of transrectal prostatic ultrasound is extremely high, while the risk of overestimation of the true prostatic volume and weight (later measured in the various studies on the anatomic piece) ranges between 4 and 10\% (21-28).

As regards the identification of prostatic nodules suspected of growth processes, it should be noted that $60 \%$ of them appear hypoechogenic, 30\% isoechogenic and $10 \%$ hyperechogenic.

Therefore, the overall diagnostic accuracy of this method alone is about $30 \%$ (this is why in most cases prostatic biopsy sampling is done randomly, in the absence of ultrasound areas raising suspicion (19-20).

The presence of a hypoechogenic image alone is not the only criterion indicating the need for prostatic biopsy.

The criteria for mapping prostatic biopsies are clinical and based on the PSA values and trend, on rectal exploration, the presence of risk factors, and also on the prostatic volume and ultrasound findings.

Granulomatous prostatitis (acute or chronic) can induce hypoechogenic modulations that are indistinguishable from those of neoplasia.

Finally, as regards the use of transrectal ultrasound to assess the perianastomotic region, the diagnostic accuracy of this investigation is strictly linked to the total 
PSA value. The positive predictive value is about $65 \%$, and the negative predictive value about 20\% (15).

For all lesions suspected to be cancerous, ultrasound alone can never replace biopsy.

\section{Notes ON CLINICAL PRACTICE}

- Use tissue harmonic imaging to reduce reverberation artifacts and obtain better detail.

- Indicate any difficulties encountered while performing the investigation (patient's collaboration and constitution, presence of bowel gas, presence of artifacts due to insufficient bowel cleansing), underlining any limits of the test and so its diagnostic value.

- If the prostate is larger than normal, its morphology may vary, especially in cases of prostatic hyperplasia.

- When performing ultrasound guidance for prostatic biopsy sampling, it is useful to ask the patient to void the bladder after the diagnostic phase

- The longitudinal diameter of the seminal vesicles varies according to the size of the gland and also the degree of bladder repletion.

- In cases with many gross calcifications along the cleavage plane between the pars adenomatosa and pars peripherica, in the periureteral intra-adenomatous site, the shadow created by the calcifications may make ultrasound exploration of the bladder or pars peripherica difficult.

\section{THE ROLE OF ECOCOLORDOPPLER}

Color Doppler and power Doppler are generally used to identify neovascularization foci, possibly expressing abscesses (vascularization absent in the center) or tumors (29-31)

\section{NEW TECHNOLOGIES}

The limited sensitivity and specificity of gray-scales ultrasound in transrectal prostatic ultrasound has led to the adoption of new technologies based on the different vascular pattern identifiable in neoplastic foci, and hence on Doppler techniques. The use of 3D ultrasound and Histoscanning seems to be able to reduce the overall number of cores necessary, contributing to a better definition of the target, but such investigations should only be considered in clinical studies $(20,32)$.

\section{The use of contrast medium}

Recent studies have not reported any increased sensitivity in the detection rate of prostatic tumors by contrast enhanced ultrasound (CEUS), as compared to extensive mapping $(33,34)$.

\section{Elastosonography}

The use of elastosonography increases the detection rate by about $20 \%$ as compared to traditional ultrasound, ultimately leading to a reduction in the number of necessary cores.

However, operator experience and the degree of pressure exerted on the tissues strongly limit large scale use of this technique (35).

\section{D ultrasound}

Thanks to the inclusion of the coronal plane, 3D ultrasound provides information helping to assess the seminal vesicles and ejaculatory ducts, as well as offering a better detection rate of prostatic tumors, according to some studies (20).

\section{DeVices AND tRANSDUCERS}

Real time endocavitary transducer (transrectal) with a frequency $\geq 6 \mathrm{MHz}$ (or anyway high).

High frequency is used because the prostate is superficial as compared to the probe plane (internal rectal wall):

- A linear monoplanar probe: for prostate sections along the longitudinal plane.

- A convex-linear or bi-convex biplanar probe: associates transverse and longitudinal scanning, through two orthogonal convex probes.

- A variable frequency probe (end-fire): allows transverse, longitudinal and oblique scanning.

\section{Table 1.}

Stones and hyperechogenic prostatic images.

\begin{tabular}{|l|l|l|l|l|}
\hline Pathologic mechanism & Size & Macroscopic evidence & Number & Site \\
\hline $\begin{array}{l}\text { (increased intraprostatic } \mathrm{pH} \text { and } \\
\text { increased precipitation of calcium salts) }\end{array}$ & & & \\
\hline $\begin{array}{l}\text { Endogenous } \\
\text { - Amyloid bodies } \\
\text { - Reaction to foreign body in intra-acinar site }\end{array}$ & $\begin{array}{l}\text { Macrolithiasis } \\
\text { (max. diameter } \geq 2 \mathrm{~mm})\end{array}$ & $\begin{array}{l}\text { Disseminated } \\
+/ \text { - posterior shadow }\end{array}$ & Single & Periurethral \\
$\begin{array}{l}\text { Exogenous } \\
\text { - Stasis of prostatic secretion } \\
- \text { Intraprostatic reflux } \\
\text { - Prostatitis }\end{array}$ & $\begin{array}{l}\text { Microlithiasis } \\
\text { (max. diameter } \leq 2 \mathrm{~mm})\end{array}$ & $\begin{array}{l}\text { Thickened } \\
+/ \text { - posterior shadow }\end{array}$ & Multiple & $\begin{array}{l}\text { Lobar } \\
\text { Perinodular } \\
\text { Ejaculatory ducts }\end{array}$ \\
\hline
\end{tabular}


Table 2

Definition of ultrasound characteristics of different disease pictures.

\begin{tabular}{|c|c|c|c|c|c|c|}
\hline $\begin{array}{l}\text { Disease } \\
\text { picture }\end{array}$ & Morphology & Echogenicity & Vascularization & Margins & Peculiarities & $\begin{array}{l}\text { Differential } \\
\text { diagnosis }\end{array}$ \\
\hline $\begin{array}{l}\text { Prostatic } \\
\text { hypertrophy }\end{array}$ & $\begin{array}{l}\text { Increased } \\
\text { size due } \\
\text { especially to } \\
\text { enlarged } \\
\text { pars adeno- } \\
\text { matosa }\end{array}$ & $\begin{array}{l}\text { Showing pars } \\
\text { peripherica sepa- } \\
\text { rated from pars } \\
\text { adenomatosa } \\
\text { thanks to an evi- } \\
\text { dent cleavage } \\
\text { plane and different } \\
\text { echogenicity (pars } \\
\text { adenomatosa is } \\
\text { hypoechogenic and } \\
\text { dyshomogeneous } \\
\text { as compared to } \\
\text { pars peripherica) }\end{array}$ & No variation & Free & $\begin{array}{l}\text { Shows pars peripherica separated } \\
\text { from pars adenomatosa thanks to } \\
\text { a cleavage plane and different } \\
\text { echogenicity (pars adenomatosa } \\
\text { is more hypoechogenic than pars } \\
\text { peripherica) } \\
\text { There may be nodular oval or } \\
\text { rounded areas, with distinct } \\
\text { margins, and an isoechogenic } \\
\text { appearance to the surrounding } \\
\text { parenchyma, expressing prostatic } \\
\text { hyperplasia intra-adenomatous } \\
\text { areas or focal prostatitis areas }\end{array}$ & $\begin{array}{l}\text { Abscess areas, in } \\
\text { very hypoechogenic } \\
\text { images } \\
\text { Calcification areas, } \\
\text { in very hypere- } \\
\text { chogenic images } \\
\text { Tumoral areas } \\
\text { (possible only with } \\
\text { biopsy) }\end{array}$ \\
\hline $\begin{array}{l}\text { Chronic } \\
\text { prostatitis }\end{array}$ & $\begin{array}{l}\text { Increased } \\
\text { size or no } \\
\text { change }\end{array}$ & $\begin{array}{l}\text { Tendency to be } \\
\text { increased, in } \\
\text { cases with calcifi- } \\
\text { cations as inflam- } \\
\text { matory outcomes }\end{array}$ & Variable & Free & $\begin{array}{l}\text { In cases of inveterate chronic } \\
\text { prostatitis, there may be a } \\
\text { dyshomogeneous appearance, } \\
\text { with alternating hypo-isoechogenic } \\
\text { and hyperechogenic areas }\end{array}$ & $\begin{array}{l}\text { Neoplasia, espe- } \\
\text { cially in cases of } \\
\text { granulomatous pro- } \\
\text { statitis observed in } \\
\text { subjects with a his- } \\
\text { tory of endovesical } \\
\text { chemo-immunopro- } \\
\text { phylaxis with BCG. }\end{array}$ \\
\hline
\end{tabular}

\section{Ultrasound of the scrotum}

\section{INDICATIONS}

1. To evaluate the acute scrotum: testicular trauma, ischemia, suspected torsion and infectious or inflammatory diseases $(4,7,16)$.

2. To assess palpable masses in the inguinal or scrotal site $(18,22)$.

3. To assess any asymmetry and increased volume of the scrotum (21).

4. To assess a possible scrotal hernia (13).

5. For diagnosis and staging of varicocele.

6. To evaluate male infertility.

7. In follow-up of previous lesions shown at ultrasound (10).

8. To assess cryptorchidism (12).

9. To search for an occult primitive tumor in a patient with germinal tumor metastases.

10. In follow-up of patients with a primitive testicular tumor, lymphoma or leukemia (23).

11. In follow-up after testicular surgery.

12. In diagnostic workup for anomalies observed at other imaging studies like CT, MRI or PET.

13. To assess intersexual conditions.

\section{ESSENTIAL PARAMETERS} IN THE STUDY OF THE SCROTUM (20)
1. The scrotal wall.
2. The testicular volume.
3. The testicular echostructure.
4. The epididymis (volume and echostructure).
5. Vascularization.
6. The pampiniform plexus.

\section{Preparation for the investigation AND PATIENT POSITION}

The investigation must be performed in a darkened room, to protect the patient's privacy, and the room temperature must not be cold because this could elicit the cremasteric reflex, in a more accentuated form in children, that could cause the testicle to rise up. Initially, the patient should lie supine with a scrotal support to facilitate exposure. The penis will be positioned superiorly or supero-laterally $(5,8)$.After examining the content of the scrotal sac in clinostatic position, the investigation should be continued with the patient in orthostatic position, making a careful evaluation of the venous flow of the spermatic cords. B-Mode study will already reveal 
the presence of varicose veins, but it is convenient to go on immediately to color Doppler study to examine the characteristic patterns of varicocele (11).

\section{NOTES ON CLINICAL PRACTICE AND INDICATIONS FOR ECHOCOLORDOPPLER}

The first task in scrotal ultrasound is to make a correct calculation of the testicular volume. The formula most commonly used today is the ellipsoid (volume in $\mathrm{ml}=$ product of the three diameters (in $\mathrm{cm}$ ) x 0.52) (3).

The testicles must be assessed on two planes: longitudinal and transverse.

The transverse plane is focused on the superior medial and inferior testicular portions, and the longitudinal plane on the central portion, as also medial and lateral. Once the whole testicle has been measured, the investigation continues with the epididymis (head, body and tail) (6).

The testicular measurements and echogenicity should then be compared with those of the contralateral testicle. Color Doppler can be helpful, especially in cases of acute pain (2). In this case, both longitudinal and transverse scanning is useful, as well as comparison of the two testicles. The doppler parameters must be set to analyze slow flow. Should it be impossible to visualize the flow, power Doppler can be employed to highlight the images (9).

Color Doppler is essential in the diagnosis and staging of varicocele.

\section{DeVICES AND TRANSDUCERS}

The investigation is conducted using a real time scanner, preferably with a linear transducer.

The transducer is set to scanning mode at the highest frequency of the device. In the latest ultrasound devices the frequency may range from 8 to $15 \mathrm{MHz}$ or more $(1,19)$. The transducer length may range between 4 and $8 \mathrm{~cm}$. Resolution must be sufficient to discriminate different ultrasound characteristics in any lesions observed. If there is a markedly increased volume of the scrotum, the use of lower frequencies is indicated to make a correct study of the gonads (15); alternatively it is possible to rely on the trapezoid assessment available in more modern ultrasound devices (14).

The doppler frequencies must be as high as possible to optimize the resolution and show the blood flow. Modern devices offer a frequency range of 5 to $10 \mathrm{MHz}$ (17).

\section{EXAMPLE OF FINAL REPORT}

\section{Scrotal Echocolor Doppler}

Toshiba Aplio; Examination performed with linear probe $11.5 \mathrm{MHz}$

History: Previous right orchiectomy for embryonal testicular K. Known left varicocele.

Didymi: left didymis in situ with normal echostructure and volume, markedly hyopotrophic approx $3.5 \mathrm{cc}$ (ellipsoid formula calc. $0.52 \times 3$ diameters)

Epididymi: normal echostructure and size; small cyst of head of left epididymis. Small scrotolite present.

Vascularization of didymis-epididymis: within normal limits Left pampiniform plexus: severe peritesticular ectasia with vessel diameter exceeding $4 \mathrm{~mm}$.

ColorDoppler investigation of pampiniform plexus in orthostatic position.

Left pampiniform plexus: basal reflux little modified by functional manoeuvers.

Diagnostic conclusion: left Varicocele, grade V according to Sarteschi classification.

Images to be included (not all are always indispensable, depending on the clinical picture)

1. One image of each testicle and epididymis in transverse scan.

2. One image of each testicle and epididymis in longitudinal scan

3. One image of both testicles and epididymi for direct comparison.

4. One image of the prostate in longitudinal scan showing the bladder.

5. One or more images of the pampiniform plexus at rest and under Valsalva.

6. One or more images of any palpable anomalies.

\section{IMPORTANT NOTES IN CLINICAL PRACTICE}

Table 1. Lesions of the scrotal wall.

\begin{tabular}{|l|l|l|l|}
\hline & Cause & Ultrasound appearance & Second level investigations \\
\hline Non inflammatory & $\begin{array}{l}\text { Heart failure } \\
\text { Idiopathic lymphedema } \\
\text { Lymphatic and venous obstruction } \\
\text { Epidermoid cysts }\end{array}$ & $\begin{array}{l}\text { Thickened scrotal wall, with alternating } \\
\text { hyperechogenic and hypoechogenic layers } \\
\text { (onion-like appearance) }\end{array}$ & $\begin{array}{l}\text { Thickening of the scrotal wall and presence } \\
\text { of hypoechogenic areas, showing increased } \\
\text { blood flow }\end{array}$ \\
\hline Inflammatory & Cellulitis & $\begin{array}{l}\text { Thickening of the scrotal wall with signs } \\
\text { of inflammation; gas may be visible as } \\
\text { numerous hyperechogenic foci }\end{array}$ \\
\cline { 2 - 4 }
\end{tabular}


Table 2. Inguinal or scrotal swelling.

\begin{tabular}{|l|l|l|}
\hline Non inflammatory & Ultrasound appearance & Second level investigations \\
\hline $\begin{array}{l}\text { Shows bowel wall, presence of peristalsis, hyperechogenic area if omentum present. } \\
\text { Distinguish direct or indirect if inferior epigastric artery shown by Doppler. } \\
\text { Presence of stricture (SS 90\%; SP 93\%) }\end{array}$ & CT \\
\hline $\begin{array}{l}\text { Hematocele } \\
\text { Pyocele }\end{array}$ & Anechogenic fluid collection surrounding the testicular parenchyma & \\
\hline
\end{tabular}

Table 3. Spermatic cord (22).

\begin{tabular}{|l|l|l|}
\hline & Ultrasound appearance & Second level investigations \\
\hline Varicocele & $\begin{array}{l}\text { Multiple tortuous vascular structures, hypoechogenic with variable diameters } \\
\text { exceeding } 2 \mathrm{~mm} . \text { Color Doppler set for low flow to show a characteristic flow pattern, } \\
\text { with phase alterations and retrograde filling during Valsalva (SS and SP 100\%) } \\
\text { Grading varicocele accordig to an established classification. } \\
\text { The suggested classification is the grading system according to Sarteschi Classification. }\end{array}$ & Spermiogram \\
$\begin{array}{l}\text { Tumors } \\
\text { of spermatic cord }\end{array}$ & $\begin{array}{l}\text { Lipoma, sarcoma and rhabdomyosarcoma have the same non specific } \\
\text { ultrasound appearance }\end{array}$ & $\begin{array}{l}\text { CT, and better MRI, to enhance } \\
\text { visualization of the tissues }\end{array}$ \\
\hline
\end{tabular}

Table 4. Epididymis (18).

\begin{tabular}{|l|l|}
\hline Orchi-epididymitis & $\begin{array}{l}\text { Epididymis enlarged and hyperechogen or hypoechogenic. A reactive hydrocele may be present, and if there is testicular } \\
\text { involvement the didymis will be enlarged, with a dyshomogeneous ultrasound appearance. Doppler will show hyperemia } \\
\text { and increased blood flow (peak systolic rate }>15 \mathrm{~cm} / \mathrm{sec} \text { ) }\end{array}$ \\
\hline Chronic epididymitis & Epididymis enlarged, increased echogenicity and possibly calcifications \\
\hline Epididymis masses & $\begin{array}{l}\text { Spermatocele and epididymis cysts are shown as hypoechogenic lesions that may be as much as 1-2 cm in diameter, } \\
\text { with acoustic enhancement in the posterior wall. They may contain protein fluid or spermatozoa with a low echogenicity. }\end{array}$ \\
\hline Adenomatoid tumors can be hypoechogenic, isoechogenic or hyperechogenic
\end{tabular}

Table 5. Testicle (4, 12).

\begin{tabular}{|c|c|c|}
\hline & Ultrasound appearance & Second level investigations \\
\hline Testicular torsion & $\begin{array}{l}\text { Absence of intratesticular blood flow (SS } 86 \% \text {, SP 100\%) } \\
\text { Increased testicular volume and reduced echogenicity (4-6 h) } \\
\text { After } 24 \mathrm{~h} \text {, dyshomogeneous echostructure due to vessel congestion, hemorrhage } \\
\text { and infarction. Spiral appearance under the torsion point, that appears } \\
\text { as a homogeneous extratesticular oval or rounded mass, with or without blood flow }\end{array}$ & \\
\hline Orchitis & $\begin{array}{l}\text { Hyperemia and dyshomogeneous ultrasound appearance. Increased or enhanced } \\
\text { intratesticular blood flow }\end{array}$ & \\
\hline Testicular microlithiasis & Multiple echogenic foci with no shadow (at least 5 microliths per field) & \\
\hline Benign lesions & $\begin{array}{l}\text { Cysts of tunica albuginea: may be unilocular or multilocular, with calcifications } \\
\text { Simple cysts: may be multiple or solitary, generally adjacent to the mediastinum. } \\
\text { They appear anechogenic and with no wall. } \\
\text { Epidermoid cysts: ultrasound appearance of a halo with a central area and increased } \\
\text { echogenicity or else as a mass defined by an echogenic circle, } \\
\text { or else a classic "onion" appearance. Doppler will not show blood flow } \\
\text { Ectasia of rete testis: visible at US as fluid-filled tubular structures. } \\
\text { Possible presence of cysts } \\
\text { Intratesticular varicocele: multiple, anechogenic tortuous tubular structures. } \\
\text { Bloodflow shows characteristic reflux during Valsalva }\end{array}$ & \\
\hline Malignant lesions & $\begin{array}{l}\text { Seminomatous tumors: homogeneous hypoechogenic lesions, with uniform } \\
\text { smooth margins. Very often the tumor occupies much of the parenchyma } \\
\text { Non seminomatous tumors: may have very variable US appearance: } \\
\text { dyshomogeneous echostructure ( } 71 \%) \text {, irregular or with poorly defined } \\
\text { margins (45\%), echogenic foci }(35 \%) \text { and a cystic component (61\%) } \\
\text { Lymphomas: testicles homogeneously hypoechogenic or with multifocal } \\
\text { hypoechogenic lesions of various diameters. The didymis, in diffuse forms, } \\
\text { appears hypervascularized (d.d. with orchitis) }\end{array}$ & $\begin{array}{l}\text { Tumoral markers } \\
\text { Tumoral markers }\end{array}$ \\
\hline Testicular trauma & $\begin{array}{l}\text { Rupture or interruption of the albuginea, irregular echostructure with poorly } \\
\text { defined margins. Color / power Doppler can help to show } \\
\text { the vascular pattern of the parenchyma, capsule }\end{array}$ & MRI \\
\hline
\end{tabular}




\section{Table 6.}

Color Doppler Ultrasound (CDU) grading classification of varicocele.

In accordance with Sarteschi, varicocele can be divided into five grades according

to the characteristics of the reflux and its length, and to changes during Valsalva's manoeuvre $(24,25)$.

- Grade 1: prolonged reflux in vessels in the inguinal channel only during Valsalva's manoeuvre, while scrotal varicosity is not evident in the previous grey-scale study.

- Grade 2: small posterior varicosity that reaches the superior pole of the testis and whose diameter increases after Valsalva's manoeuvre. The CDU evaluation clearly demonstrates the presence of a venous reflux in the supratesticular region only during Valsalva's manoeuvre.

- Grade 3: is characterised by vessels that appear enlarged to the inferior pole of the testis when the patient is evaluated in a standing position, while no ectasia is detected if the examination is performed in a supine position. CDU demonstrates a clear reflux only under Valsalva's manoeuvre.

- Grade 4: is diagnosed if vessels appear enlarged, even if the patient is studied in a supine position; dilatation increases in an upright position and during Valsalva's manoeuvre. Enhancement of the venous reflux after Valsalva's manoeuvre is the criteria that allows the distinction between this grade from the previous and the next one. Hypotrophy of the testis is common at this stage.

- Grade 5: is characterised by an evident venous ectasia even in an upright position. CDU demonstrates the presence of an important basal venous reflux that does not increase after Valsalva's manoeuvre.

\section{Ultrasound of the penis}

\section{INTRODUCTION}

Penile US is an essential tool in urological clinical practice both as an investigation in itself and integrated with color Doppler of the penile vascularization (1).

\section{INDICATIONS}

Indications for penile US:

1. Erectile dysfunction

2. Priapism.

3. Penile fibrosis and Plastic Induratio Penis.

4. Penile or urethral anomalies observed at physical examination

5. Neoplasia of the penis.

6. Penile trauma.

7. Thrombosis of the dorsal vein.

8. Urethral disorders (cysts, diverticuli, stenosis).

9. Stones or foreign bodies in urethra or penis.

\section{TECHNIQUE OF INVESTIGATION}

At least two scans must be performed: transverse and longitudinal. The probe is positioned dorsally or centrally to obtain a better visualization of the corpi cavernosi, the intercavernous septum, the tuniche albuginea and Buck's fascia and the urethra (3).

The transverse scan must be done in the proximal, medial and distal portions of the penis.

The longitudinal scan must be done on the two corpi cavernosi, visualizing the cavernosum artery. In addition, to study the crural portion of the corpi cavernosi, the transducer is placed perineally (4). Size, echogenicity (hyper, hypo, iso) and symmetry of the corpi cavernosi must be described and documented with appropriate images.
Any alterations of the tuniche, either echogenic or structural, must be documented by accurate measurements both on longitudinal and transverse scans. Any palpable alteration or penile anomaly must be closely studied directly on the involved zone, documented by appropriate images. Assessment of the vascular integrity is done by integrating Color Doppler (6).

To study of the urethra $(2,5)$, hydrosoluble gel is injected through a catheter positioned at the level of the navicular fossa; longitudinal scans are done to study any alterations of the urethral lumen (7-9)

\section{SPECIFIC devices}

Penile US is done in real time B-mode scanning, using a linear probe with a frequency of $7.5 / 10 \mathrm{MHz}$ and more (10).

\section{Penile Echo Color Doppler}

Penile echocolor Doppler (1) is generally performed in the following cases:

- Erectile dysfunction [after Intra Cavernous injection (FIC) of PGE P $_{1}$

- Peyronie's disease.

- To assess penile morphology and vascularization after trauma.

- In cases of blood collection or infection.

\section{Methodology}

Assessment pre FIC:

- The investigation must be performed in calm surroundings avoiding outside interruptions. Detailed explanation of the different phases must be given, as 
well as of the possible complications, obtaining written informed consent.

- The basal study must include longitudinal and transverse scans to make an accurate study of the corpora cavernosa, corpus spongiosum, intercavernous septum, the morphology of the cavernous arteries, the gland and the urethra. The cavernous arteries are shown as parallel lines, fine and echogenic, and any anatomical variants, even lacking clinical significance (e.g. duplication of the cavernous artery must be documented) (2).

FIC:

- Single intracavernous injection of $\mathrm{PGE}_{1}$ in basal cavernous site, at variable doses $(2.5 \mathrm{mcg}$ in young, psychogenic men with a high risk of priapism due to correlated disease) and if necessary redosing. Remember that a state of anxiety in the patient could delay the effect of the drug.

\section{Post FIC assessment:}

- Spectral Doppler must be done at 0,5,10,15,20,25 and 30 minutes after FIC at the level of the proximal third of the cavernous arteries and/or in crural site.

- Measurement of Peak Systolic Velocity (PSV), Telediastolic Velocity (TDV) and Resistence Index (RI) using an ideal spectral angle of $60^{\circ}$.

- Manual or visual stimulation is not usually necessary to obtain an adequate erection.

- If the flowmetry result is considered adequate, the investigation can be interrupted before the measurements at 25 and 30 minutes.

- After flowmetry it is useful to make a morphological study of the penile vascularization by Power Imaging, to assess the microcirculation, describing whether the helical branches are visible or not, and their angle of incidence on the cavernous artery (normally $>90^{\circ}$ ) (3). This method is also used to visualize traumatic lesions (4).

- The dynamic phase after FIC is also useful to study Peyronie's disease plaques, both in B-mode and Color Power Imaging, as well as fibrosis, structural variations and any zones of venous leakage around the plaques.

- Describe the degree of erectile response in terms of tumescence and rigidity at 20/30 minutes after FIC.

\section{Diagnostic criteria:}

- B-mode: Detailed description of the anatomical symmetry of the corpi cavernosi, fibrous septum, any plaques or calcifications of the intracavernous zone or tuniche, any hypoechogenic lesions.

- Arterial compartment: Any increased diameter post FIC, intravascular flow. Values of PSV $>35 \mathrm{~cm} / \mathrm{sec}$ are considered normal in the literature, between 25 and $35 \mathrm{~cm} / \mathrm{sec}$ "borderline", that should be integrated with the degree of erectile response, values $<25 \mathrm{~cm} / \mathrm{sec}$ are considered pathologic (5).

- Venous compartment: With an increased intracavernous pressure and so increased PSV there is a decrease in TDV that may become negative with inver- sion of the diastolic wave, a sign of integrity of the venoocclusive mechanism. A persistence of TDV values $>5-7 \mathrm{~cm} / \mathrm{sec}$ throughout all the phases of the test indicates a deficit of the venoocclusive mechanism.

- It is important always to integrate flowmetry data with the degree of erectile response to FIC because a poor rigidity (low dosage of PGE1, a state of anxiety) and hence a minor arterial inflow will limit the degree of response of the venous compartment and hence the sensitivity and specificity of the test (6).

- In the findings, note the patient's psychoemotional approach to the test.

\section{After the test:}

- Ascertain complete detumescence before the patient leaves, informing him of the possibility of a prolonged erection/priapism and the management of this complication, as well as how to obtain further assistance if necessary.

- Produce an accurate report with appropriate images both of the flowmetry and the morphology.

\section{Tools}

High frequency $7.5 \mathrm{MHz}$ or more linear transducer, US device equipped with Color-Power Spectral Doppler; high Doppler frequencies are advisable (higher than 10 $\mathrm{MHz}$ ) because they provide optimal resolution and facilitate the examination of intravasal flow (7)

\section{EXAMPLE OF FINAL REPORT}

Test performed with linear probe $(7.5 / 10) \mathrm{MHz}$. Test performed in basal conditions and after drug infusion of ... mcg. of prostaglandins (PGE1); patient gave written informed consent to the procedure.

Normal conformation of the corpi cavernosi, that appear symmetrical and of the corpus spongiosus of the urethra.; otherwise describe any alterations/irregularities of the tunica and septum, such as hyper-reflection, hyperechogenicity and any images suggesting Induratio Penis Plastica.

Cavernous arteries present, with a twisted course, pulsating. After FIC, increased volume of the corpi cavernosi with dilation and straightening of the cavernous arteries, that appear pulsating/non pulsating.

Erectile response to FIC at .... minutes

(poor/fair/good/excellent) for tumescence and rigidity with/without deviation of the penile axis (in cases of deviation describe whether it is dorsal, ventral or lateral, and the degree)

Grade of EAS (Erection Assessment Scale): 1 to 5 (No erectile response/full rigidity)

Flowmetry study performed in crural site:

measurement of the systo-diastolic velocities with spectral Doppler analysis at 5,10,15,20,25 and 30 minutes after FIC. PSV (peak systolic velocity) equal to ....cm/sec on left and ... cm/sec on right at ... minutes after FIC showing normal/reduced arterial inflow. TDV (tele diastolic velocity) ... c $/ \mathrm{sec}$ with/ without progressive reduction or with/without negativization of the dias- 
tolic wave at 20/30 minutes after FIC, showing integrity/deficit of the veno-occlusive mechanism. IR $</=/>1$

Phase 3 obtained at ... minutes

Phase 4 obtained/not obtained at ....minutes

Morphological study performed with Color Power Doppler: Cavernous arteries morphologically normal, well distended and straightened.

Good/Fair/Poor visualization of the helicine branches by $1^{\circ}, 2^{\circ}$ and $3^{\circ}$ presenting an angle of incidence $<1>90^{\circ}$, demonstrating integrity/deficit of the microcirculation (In cases of IPP) Presencelabsence of peri-plaque Venous Leakage

At ..... minutes after FIC there is/is not progressive penile detumescence.

Psychoemotional attitude to test: poor/fair/good

Images to include (not all are indispensable, depending on clinical picture)

1. Two basic images.

2. Six doppler spectral images with relative flowmetry values.

3. Two images showing microcirculation.

\section{References}

\section{Introduction}

1. Documento SIUMB per le Linee Guida in Ecografia. Giornale Italiano di Ecografia (SIUMB Editore) I.R. al vol. 8-n 4. December 2005:

2. AUA, AIUM Practice Guideline for the Performance of an Ultrasound examination in the practice of urology, 2011. www.aium.org

3. Linee guida SIEOG Società Italiana di Ecografia Ostetrico Ginecologica, Edition 2010.

4. Bevelacqua JJ. Practical and effective ALARA. Health Phys. 2010; 98 (Suppl 2):S39-47.

5. Eeg KR, Khoury AE, Halachmi S, et al. Single center experience with application of the ALARA concept to serial imaging studies after blunt renal trauma in children--is ultrasound enough? J Urol. 2009; 181:1834-40; discussion 1840.

6. Rutala WA. Disinfection and Sterilization in Healthcare: New CDC Guidelines.

7. Velázquez-Estades LJ, Wanger A, Kellaway J, et al. Microbial contamination of immersion biometry ultrasound equipment. Ophthalmology. 2005; 112:e13-8.

\section{Ultrasound scanning of the kidney}

1. Griffiths GJ, Cartwright G, McLachlan MSF. Estimation of renal size from radiographs: is the effect worthwhile? Clin Radiol. 1974; 26:249-256.

2. Dure-Smith P, McArdle GH. Tomography during excretory urography. Technical aspects. Br J Radiol. 1972; 45:896-901.

3. De Sanctis JT, Connoly SA, Bramson RT. Effect of patient position on sonographically measured renal length in neonates, infants, and children. Am J Roentgenol. 1998; 170:1381-1383.
4. Jones TB, Riddick LR, Harpen J, et al. Ultrasonographic determination of renal mass and renal volume. J Ultrasound Med. 1983; 2:151-154.

5. Hricak H, Lieto RP. Sonographic determination of renal volume. Radiology. 1983; 148: 311-312.

6. Partik BL, Stadler A, Schamp S, et al. 3D versus 2D ultrasound: accuracy of volume measurement in human cadaver kidneys. Invest Radiol. 2002; 37:489-495.

7. Brandt TD, Neiman HL, Dragowski MJ, et al. Ultrasound assessment of normal renal dimension. J Ultrasound Med. 1982; 1:49-52.

8. Emamian SA, Nielsen MB, Pedersen JF. Intraobserver and interobserver variations in sonographic measurements of kidney size in adult volunteers. A comparison of linear measurements and volumetric estimates. Acta Radiol. 1995; 36:399-401.

9. Fiorini F, Barozzi L. The role of ultrasound in the study of medical nephropathy. J Ultrasound. 2007; 10:4, 161-167.

10. Granata A, Bigi MC, Andrulli S, et al. L'analisi del segnale Doppler. In L'ecocolorDoppler nella pratica nefrologica. Granata A, Fiorini F, D’Amelio A, Logias F, Andrulli S. Vol 1, pp.49-61, 2010.

11. Piscaglia F, Nolsøe C, Dietrich CF, et al. The EFSUMB guidelines and recommendations on the clinical practice of contrast enhanced ultrasound (CEUS): Update 2011 on non-hepatic applications. Ultraschall Med. 2012; 33:5-7.

\section{Ultrasound of the bladder}

1. Kanu GB. Ultrasonography of the Urinary Bladder, J Med Ultrasound. 2010; 18:105-114.

2. Seung HK. Ultrasound of the Urinary Bladder, Revisited J Med Ultrasound. 2007; 15:77-90.

3. Aganovic D, Hasanbegovic M, Prcic A, et al. Which is a better indicator of bladder outlet obstruction in patients with benign prostatic enlargement--intravesical protrusion of prostate or bladder wall thickness? Med Arh. 2012; 66:324-8.

4. Athanasiou S1, Khullar V, Boos K, et al. Imaging the urethral sphincter with three-dimensional ultrasound. Obstet Gynecol. 1999 Aug; 94:295-301.

5. Blatt A, Chan L. The importance of bladder wall thickness in the assessment of overactive bladder. Current Bladder Dysfunction Reports 2009; 4:220-224.

6. Franco G, De Nunzio C, Leonardo C, et al. Ultrasound assessment of intravesical prostatic protrusion and detrusor wall thickness--new standards for noninvasive bladder outlet obstruction diagnosis? J Urol. 2010; 183:2270-4.

7. Galosi AB, Mazzaferro D, Lacetera V, et al. Modifications of the bladder wall (organ damage) in patients with bladder outlet obstruction: ultrasound paremeters. Arch Ital Urologia Androl. 2012; 84:4: 263-267.

8. Oelke M. International Consultation on Incontinence-Research Society (ICI-RS) report on non-invasive urodynamics: the need of standardization of ultrasound bladder and detrusor wall thickness measurements to quantify bladder wallhypertrophy. Neurourol Urodyn. 2010; 29:634-9.

9. Bright E, Oelke M, Tubaro A, Abrams P. Ultrasound estimated bladder weight and measurement of bladder wall thickness-Useful noninvasive methods for assessing the lower urinary tract? J Urol. 2010; 184:1847-1854.

10. Robinson D, Cardozo L. Can ultrasound replace ambulatory uro- 
dynamics when investigating women with irritative urinary symptoms? BJOG. 2002; 109:145-8.

11. Costantini S, Esposito F, Nadalini C, et al. Ultrasound imaging of the female perineum :the effect of vaginal delivery on pelvic floor dynamics. Ultrasound Obstet Gynecol. 2006; 27:183-7.

12. Costantini S, Nadalini C, Esposito F, et al. Perineal ultrasound evaluation of the urethrovesical Junction angle and urethral mobility in nulliparous women and women following vaginal delivery. Int Urogynecol J Pelvic Floor Dysfunction. 2005; 16:455-9.

13. Granados Loarca EA, Alcahe VR, de Leon López H, Echeverria Reyes J. The usefulness of perineal ultrasound in urinary incontinence in women Arch Esp Urol. 1999; 52:778-82.

14. Masata J, Martan A, Halaska M, Otsenásek M. Ultrasonography of the funneling of the urethra Ceska Gynekol. 2000; 65:87-90.

15. Martan A, Masata J, Halaska M, et al. The effect of bladder filling on changes in ultrasonography parameters of the lower urinary tract in women with urinary stress incontinence Ceska Gynekol. 2000; 65:10-3.

16. Minardi D, Piloni V, Amadi A, et al. Correlation between urodynamics and perineal ultrasound in female patients with urinary incontinence. Neurol and Urodyn. 2007; 26:176-182.

17. Peschers UM, Fanger G, Schaer GN, et al. Bladder neck mobility in continent nulliparous women. BJOG. 2001; 108:320-4.

18. Reilly ET, Freeman RM, Waterfield MR, et al. Prevention of postpartum stress incontinence in primigravidae with increased bladder neck mobility: a randomised controlled trial of antenatal pelvic floor exercises. Br J Obstet Gynecol. 2002; 109:68-76.

19. Schaer GN, Koechli OR, Schuessler B, Haller U. Perineal ultrasound: determination of reliable examination procedures. Ultrasound Obstet Gynecol. 1996; 7:347-52.

20. Siracusano S, Bertolotto M, d'Aloia G, et al. Colour Doppler ultrasonography of female urethral vascularization in normal young volunteers: a preliminary report. BJU Int. 2001; 88:378-81.

21. Strasser H, Ninkovic M, Hess $M$, et al. Anatomic and functional studies of the male and female urethral sphincter World J Urol. 2000; 18:324-9.

22. Tunn $R$, Schaer $G$, Peschers $U$, et al. Update recommendations on ultrasonography in urogynecology. Int Urogynecol J. 2005; 16:236-241.

23. Umek WH, Obermair A, Stutterecker D, et al. Three-dimensional ultrasound of the female urethra: comparing transvaginal and transrectal scanning. Ulrasound Obstet Gynecol. 2001; 17:425-30.

24. Piscaglia F, Nolsøe C, Dietrich CF, et al. The EFSUMB guidelines and recommendations on the clinical practice of contrast enhanced ultrasound (CEUS): Update 2011 on non-hepatic applications. Ultraschall Med. 2012; 33:5-7.

\section{TEXTS}

A literature search of guidelines and reviews on the use of ultrasound in bladder studies published in the last 10 years was made.

AIUM Practice Guideline for Documentation of an Ultrasound Examination. 2008 American Institute of Ultrasound in Medicine.

AIUM Official Statements Training Guidelines for Physicians Who Evaluate and Interpret Diagnostic Ultrasound Examinations. American Institute of Ultrasound in Medicine 2011.

Standards and Guidelines for the Accreditation of Ultrasound Practices. 2011 American Institute of Ultrasound in Medicine.
Documento SIUMB per le linee guida in Urologia. Giornale Italiano di ecografia I.R. al vol. 8 n. 42005.

EAU Guidelines on Urinary Incontinence. Eur Urol 59 (2011) $387-400$.

Guidelines on Non-muscle-invasive Bladder Cancer (TaT1 and CIS). EAU 2012.

Guidelines on Pain Management. EAU 2012.

\section{Prostate and seminal vesicles}

PROSTATIC ULTRASOUND SCANNING WITH THE SUPRAPUBIC TECHNIQUE

1. Tokgöz Ö, Tokgöz H, Unal I, et al. Diagnostic values of detrusor wall thickness, postvoid residual urine, and prostate volume to evaluate lower urinary tract symptoms in men. Diagn Interv Radiol. 2012; 18:277-81.

2. Società Italiana di Radiologia Medica -Linee guida della diagnostica per immagini 2009- http://www.sirm.org/it/documenti/ cat_view/66-linee-guida.html

3. American College of Radiology -Ultrasound Guidelineshttp://www.acr.org/Quality-Safety/Standards-Guidelines/PracticeGuidelines-byModality/Ultrasound

4. European Association of Urology -2012 Guidelineshttp://www.uroweb.org/guidelines/online-guidelines

5. American Association of Urology Guidelines - http:// www.auanet .org/content/clinical-practice-guidelines/clinical-guidelines.cfm

6. Stravodimos KG, Petrolekas A, Kapetanakis T, et al. TRUS versus transabdominal ultrasound as a predictor of enucleated adenoma weight in patients with BPH: a tool for standard preoperative work-up? Int Urol Nephrol. 2009; 41:767-71.

7. Strasser H, Janetschek G, Reissigl A, Bartsch G. Prostate zones in three dimensional transrectal ultrasound. Urology. 1996; 47:485-90.

8. Tong S, Downey DB, Cardinal HN, Fenster A. A three dimensional ultrasound prostate imaging system. Ultrasound Med Biol. 1996; 22-6: 735-46.

9. Aarnick RG, Huynen AL, Giesen RJ, et al. Automated prostate Volume determination with double ultrasonographic imaging. J Urol. 1995; 153:1549-54.

\section{TRANSRECTAL PROSTATIC ULTRASOUND}

1. Società Italiana di Radiologia Medica -Linee guida della diagnostica per immagini 2009- http://www.sirm.org/it/documenti/ cat_view/ 66-linee-guida.html.

2. American College of Radiology -Ultrasound Guidelineshttp://www.acr.org/Quality-Safety/Standards-Guidelines/PracticeGuidelines-byModality/Ultrasound.

3. European Association of Urology - 2012 Guidelines - http://www. uroweb.org/guidelines/online-guidelines.

4. American Association of Urology Guidelines http://www.auanet. org/content/clinical-practice-guidelines/clinical-guidelines.cfm.

5. Stravodimos KG, Petrolekas A, Kapetanakis T, et al. TRUS versus transabdominal ultrasound as a predictor of enucleated adenoma weight in patients with BPH: a tool for standard preoperative work-up? Int Urol Nephrol. 2009; 41:767-71.

6. Ash D, Flynn A, Battermann J, et al. ESTRO/EAU/EORTC recommendations on permanent seed implantation for localized prostate cancer. Radiother Oncol. 2000; 57:315-21. 
7. Meraj S, Nagler HM, Homel P, et al. Radical prostatectomy: size of the prostate gland and its relationship with acute perioperative complications. Can J Urol. 2003; 10:1743-1748.

8. Giubilei G, Ponchietti R, Biscioni S, et al. Accuracy of prostate volume measurements using transrectal multiplanar three dimensional sonography. Int J Urol. 2005; 12:936-8.

9. Pierangeli T, Muraro GB. Role of 3D-ultrasonography in the assessment of transitional zone PSA. Arch Ital Urol Androl. 2002; 74:282-4.

10. Strasser H, Janetschek G, Reissigl A, Bartsch G. Prostrate zones in three dimensional transrectal ultrasound. Urology. 1996; 47:485-90.

11. Aarnick RG, Huynen AL, Giesen RJ, et al. Automated prostate Volume determination with double ultrasonographic imaging. J Urol. 1995; 153:1549-54.

12. Tong S, Downey DB, Cardinal HN, Fenster A. A threedimensional ultrasound prostate imaging system. Ultrasound Med Biol. 1996; 22-6:735-46

13. Watanabe H, Igari D, Tanahashi Y, et al. Measurement of size and weight of the prostate by means of transrectal ultrasonotomography. Tohoku J Exp Med. 1974; 114:277-85.

14. Aarnink RG, De La Rosette JMCH, Debruyne FMJ, Wijkstra H. Reproducibility of prostate volume measurements from transrectal ultrasonography by an automated and a manual technique. Br J Urol. 1996; 78 :219-23.

15. Martino P, Scattoni V, Galosi AB, et al. Role of imaging and biopsy to assess local recurrence after definitive treatment for prostate carcinoma (surgery, radiotherapy, cryotherapy, HIFU). World J Urol. 2011; 29:595-605

16. Uchida T, Ohori M, Soh S, et al. Factors influencing morbidity in patients undergoing transurethral resection of the prostate. Urology. 1999; 53:98-105

17. Galosi AB, Montironi R, Fabiani A, et al. Cystic lesions of the prostate gland: an ultrasound classification with pathological correlation. Journal of Urology. 2009; 181:647-657.

18. Shinbo H, Kurita Y. Application of ultrasonography and the resistive index for evaluating bladder outlet obstruction in patients with benign prostatic hyperplasia. Curr Urol Rep. 2011; 12:255-60.

19. Purohit RS, Shinohara K, Meng MV, Carroll PR. Imaging clinically localized prostate cancer. Urol Clin North Am. 2003; 30:279-93.

20. Martino P, Palazzo S, Bufo P, et al. Three-dimensional digital ultrasound for early staging of prostatic adenocarcinoma Jour. Urol. $2000 ; 164: 456$

21. Alkan I, Turkeri L, Biren T, et al. Volume determinations by transrectal ultrasonography in patients with benign prostatic hyperplasia: correlation with removed prostate weight. Int Urol Nephrol. 1996; 28:517-523.

22. Loeb S, Han M, Roehl KA, Aet al. Accuracy of prostate weight estimation by digital rectal examination versus transrectal ultrasonography. J Urol. 2005; 173:63-65.

23. Lee JS, Chung BH. Transrectal ultrasound versus magnetic resonance imaging in the estimation of prostate volume as compared with radical prostatectomy specimens. Urol Int. 2007; 78:323-327.

24. Rahmouni A, Yang A, Tempany CM, et al. Accuracy of in vivo assessment of prostatic volume by MRI and transrectal ultrasonography. J Comput Assist Tomogr. 1992; 16:935-940.

25. Cabello Benavente R, Jara Rascon J, Monzo JI, et al. Volume determinations of the whole prostate and of the adenoma by transrectal ultrasound: correlation with surgical specimen. Actas Urol Esp. 2006; 30:175-180.

26. Bland JM, Altman DG. Statistical methods for assessing agreement between two methods of clinical measurement. Lancet. 1986; 1:307-310

27. Nathan MS, Seenivasagam K, Mei Q, et al. Transrectal ultrasonography: why are estimates of prostate volume and dimension so inaccurate? Br J Urol. 1996; 77:401-407.

28. Novis MI, Baroni RH, Cerri LM, et al. Clinically low-risk prostate cancer: evaluation with transrectal doppler ultrasound and functional magnetic resonance imaging. Clinics (Sao Paulo). $2011 ; 66: 27-34$

29. Morelli G, Pagni R, Mariani $C$, et al. Results of vardenafil mediated power Doppler ultrasound, contrast enhanced ultrasound and systematic random biopsies to detect prostate cancer. J Urol. 2011; 185:2126-31.

30. Taverna G1, Morandi G, Seveso M, et al. 31. Colour Doppler and microbubble contrast agent ultrasonography do not improve cancer detection rate in transrectal systematic prostate biopsy sampling. BJU Int. 2011; 108:1723-7.

31. Braeckman J, Autier P, Garbar C, et al. Computer-aided ultrasonography (HistoScanning): a novel technology for locating and characterizing prostate cancer. BJU Int. 2008; 101:293-8.

32. Piscaglia F, Nolsøe C, Dietrich CF, et al. The EFSUMB guidelines and recommendations on the clinical practice of contrast enhanced ultrasound (CEUS): Update 2011 on non-hepatic applications. Ultraschall Med. 2012; 33:5-7.

33. Jiang J, Chen Y, Zhu Y, et al. Contrast-enhanced ultrasonography for the detection and characterization of prostate cancer: correlation with microvessel density and Gleason score. Clin Radiol. 2011; 66:732-7..

34. Strazdina A, Krumina G, Sperga M. The value and limitations of contrast-enhanced ultrasound in detection of prostate cancer. Anticancer Res. 2011; 31:1421-6.

35. Giurgiu CR, Manea C, Crisan N, et al. Real-time sonoelastography in the diagnosis of prostate cancer. Med Ultrason. 2011; 13:5-9.

\section{Ultrasound of the scrotum}

1. Akin EA, Khati NJ, Hill MC. Ultrasound of the scrotum. Ultrasound Q. 2004; 20:181-200.

2. Baldisserotto M, de Souza JC, Pertence AP, Dora MD. Color Doppler sonography of normal and torsed testicular appendages in children. AJR Am J Roentgenol. 2005; 184:1287-1292.

3. Basu S, Howlett DC. High-resolution ultrasound in the evaluation of the nonacute testis. Abdom Imaging. 2001; 26:425-432.

4. Bhatt S, Dogra VS. Role of US in testicular and scrotal trauma. Radiographics. 2008; 28:1617-29.

5. Bertolotto M; Trombetta C (Eds). Scrotal Pathology. 1st edition. Berlin: Springer 2012

6. Casalino DD, Kim R. Clinical importance of a unilateral striated pattern seen on sonography of the testicle. AJR Am J Roentgenol. 2002: 178:927-930.

7. Dogra VS, Bhatt S. Acute painful scrotum. Radiol Clin North Am. 2004; 42:349-363

8. Dogra VS, Gottlieb RH, Oka M, Rubens DJ. Sonography of the scrotum. Radiology. 2003; 227:18-36. 
9. Dogra VS, Rubens DJ, Gottlieb RH, Bhatt S. Torsion and beyond: new twists in spectral Doppler evaluation of the scrotum. J Ultrasound Med. 2004; 23:1077-1085.

10. Dogra VS, Gottlieb RH, Rubens DJ, Liao L. Benign intratesticular cystic lesions: US features. Radiographics. 2001.

11. Gorman B, Carroll BA. Scrotal sonography. In: Rumack CM, Wilson SR, Charboneau JW (eds). Diagnostic Ultrasound, 3rd ed. Chicago, IL: CV Mosby Co. 2005; 849-888.

12. Hörmann M, Balassy C, Philipp MO, Pumberger W. Imaging of the scrotum in children. Eur Radiol. 2004; 14:974-983.

13. Karmazyn B, Steinberg R, Kornreich L, et al. Clinical and sonographic criteria of acute scrotum in children: a retrospective study of 172 boys. Pediatr Radiol. 2005; 35:302-310.

14. Kim W, Rosen MA, Langer JE, Banner MP, et al. US MR imaging correlation in pathologic conditions of the scrotum. Radiographics. 2007; 27:1239-53.

15. Mirochnik B, Bhargava P, Dighe MK, Kanth N. Ultrasound evaluation of scrotal pathology. Radiol Clin North Am. 2012; $50: 317-32$

16. Pavlica P, Barozzi L. Imaging of the acute scrotum. Eur Radiol. 2001; 11:220-8.

17. Pearl MS, Hill MC. Ultrasound of the scrotum. Semin Ultrasound CT MR. 2007; 28:225-48.

18. Philips S, Nagar A, Dighe M, et al. Benign non-cystic scrotal tumors and pseudotumors. Acta Radiol. 2012 Feb 1; 53:102-11.

19. Ragheb D, Higgins JL Jr. Ultrasonography of the scrotum: technique, anatomy, and pathologic entities. J Ultrasound Med. 2002; 21:171-85

20. Sudakoff GS, Quiroz F, Karcaaltincaba M, Foley WD. Scrotal ultrasonography with emphasis on the extratesticular space: anatomy, embryology, and pathology. Ultrasound Q. 2002; 18:255-273.

21. Woodward PJ, Sohaey R, O'Donoghue MJ, Green DE. From the archives of the AFIP: tumors and tumorlike lesions of the testis-radiologic-pathologic correlation. Radiographics. 2002; 22:189-216.

22. Yang DM, Kim SH, Kim HN, et al. Differential diagnosis of focal epididymal lesions with gray scale sonographic, color Doppler sonography.

23. Galosi AB, Lacetera V, Muzzonigro G. Clinica delle malattie testicolari di interesse ecografico. UROLOGIA vol 75, n.4, S12, 2008: pag s59-66.

24. Chiou RK, Anderson JC, Wobig RK, et al. Color Doppler ultrasound criteria to diagnose varicoceles: correlation of a new scoring system with physical examination. Urology. 1997; 50:953-6.

25. Liguori G, Trombetta C, Garaffa G, et al. Color Doppler ultrasound investigation of varicocele. World J Urol. 2004; 22(5):378-81.

\section{TEXTS}

American Institute of Ultrasound in Medicine; American College of Radiology; Society of Radiologists in Ultrasound. AIUM practice guideline for the performance of scrotal ultrasound examinations. $J$ Ultrasound Med. $2011 ; 30$ (1):151-5.

Practice Guideline for the Performance of an Ultrasound Examination in the Practice of Urology http://www.auanet.org/content/education-and-meetings/aium-ultrasound-guidelines.cfm

\section{Ultrasound of the penis}

1. Bassiouny HS, Levine LA. Penile duplex sonography in the diagnosis of venogenic impotence.J Vasc Surg. 1991; 13:75-82.

2. Bearcroft PW, Berman LH. Sonography in the evaluation of the male anterior urethra. Clin Radiol. 1994; 49:621-626.

3. Broderick GA, Lue TF. The penile blood flow study: evaluation of vasculogenic impotence. In:Jonas $U$, Thon W, F Stief CG (eds). Erectile Dysfunction. Berlin, Germany: Springer-Verlag; 1991.

4. Chou YH, Tiu CM, Pan HB, et al. High-resolution real-time ultrasound in Peyronie's disease.J Ultrasound Med. 1987; 6:67-70.

5. Choudhary S, Singh P, Sundar E, Kumar S, Sahai A. A comparison of sonourethrography and retrograde urethrography in evaluation of anterior urethral strictures. Clin Radiol. 2004; 59:736-742.

6. Kadiou A, Tefekli A, Erol H, Cayan S, Kandirali E. Color Doppler ultrasound assessment of penile vascular system in men with Peyronie's disease. Int J Impot Res. 2000; 12:263-267.

7. Kim B, Kawashima A, LeRoy AJ. Imaging of the male urethra. Semin Ultrasound CT MR 2007; 28:258-273

8. King BF, Lewis RW, McKusick MA, Evaluation of impotence. In: Bennett $A H$ (ed). Impotence: Diagnosis and management of erectile dysfunction. Philadelphia, PA: WB Saunders Co; 1994

9. Morey AF, McAninch JW. Sonographic staging of anterior urethral strictures. J Urol. 2000; 163:1070-1075.

10. Patel U, Lees WR. Penile sonography. In: Solbiati L, Rizzatto G (eds). Ultrasound of Superficial Structures. London, England: Churchill Livingstone; 1995: 229-242.

\section{PENILE ECHO COLOR DOPPLER}

1. Halls J, Bydawell G, Patel U. Erectile dysfunction: the role of penile Doppler ultrasound in diagnosis. Abdom Imaging. 2009; 34:712-25.

2. Broderick GA. Evidence based assessment of erectile dysfunction. Int J Impot Res. 1998; 10 Suppl 2:S64-73; discussion S7-9.

3. Benson CB, Aruny JE, Vickers MA, Jr. Correlation of duplex sonography with arteriography in patients with erectile dysfunction. AJR Am J Roentgenol. 1993; 160:71-3.

4. Quam JP, King BF, James EM, et al. Duplex and color Doppler sonographic evaluation of vasculogenic impotence. AJR Am J Roentgenol. 1989; 153:1141-7.

5. Patel U, Amin Z, Friedman E, et al. Colour flow and spectral Doppler imaging after papaverine-induced penile erection in 220 impotent men: study of temporal patterns and the importance of repeated sampling, velocity asymmetry and vascular anomalies. Clin Radiol. 1993; 48:18-24.

6. Fitzgerald SW, Erickson SJ, Foley WD, et al. Color Doppler sonography in the evaluation of erectile dysfunction: patterns of temporal response to papaverine. AJR Am J Roentgenol. 1991; 157:331-6.

7. Bertolotto M. (ed) Color Doppler US of the penis. Springer, Berlin Heidelberg 2008, ISBN:978-3-540-36676-8.

\section{ACKNOWLEDGMENT}

We would like to thank Mary V.C. Pragnell, B.A., for language assistance. 


\section{Correspondence}

\section{Coordinators}

Pasquale Martino, MD (Corresponding Author)

Department of Emergency and Organ Transplantation-Urology I,

University "Aldo Moro", Bari, Italy

pasqualeluciomartino@libero.it

Andrea Benedetto Galosi, MD

Division of Urology, "Murri" General Hospital, ASUR Marche,

Fermo, Italy

galosiab@yahoo.it

\section{Authors}

Marco Bitelli, MD

Urologist, Rome, Italy

Paolo Consonni, MD

U.O. Urologia - Casa di Cura "S. Maria", Castellanza (VA), Italy

Fulvio Fiorini, MD

Nefrologia SOC - Azienda Sanitaria ULSS 18 Rovigo, Italy

fiorini.fulvio@azisanrovigo.it

Antonio Granata, MD

U.O. Nefrologia e Dialisi - ASP Agrigento, Agrigento, Italy

Roberta Gunelli, MD

U.O. Urologia Ospedale G.B. Morgagni-L. Pierantoni

Azienda USL di Forl

Via Carlo Forlanini, 34 - Forli, Italy

Giovanni Liguori, MD

Department of Urology, University of Trieste, Ospedale di Cattinara, Trieste, Italy

Silvano Palazzo, MD

Department of Emergency and Organ Transplantation-Urology I,

University "Aldo Moro", Bari, Italy

silvano.palazzo@alice.it
Nicola Pavan, MD

Urologist, Trieste, Italy

Vincenzo Scattoni, MD

Department of Urology, University Vita-Salute,

Scientific Institute San Raffaele, Milan, Italy

scattoni.vincenzo@hsr.it

Guido Virgili, MD

Department of Urology, University of Tor Vergata, Rome, Italy guidovirgili@tiscali.it

\section{Reviewers}

Libero Barozzi, MD

Società Italiana Radiologia

Emergency, Surgery and Transplants Department

Radiology Unit S. Orsola-Malpighi University Hospital

Via Albertoni 10, Bologna, Italy

Michele Bertolotto, MD

UCO di Radiologia, Dipartimento di Scienze Mediche,

Chirurgiche e della Salute, Università degli Studi di Trieste,

Ospedale di Cattinara - Strada di Fiume 447, Trieste, Italy

Andrea Fandella, MD

Divisione Urologica, Casa di Cura Giovanni XXIII

Monastier (Treviso), Italy

afandella@alice.it

Paolo Rosi, MD

Clinica Urologica ed Andrologica, University of Perugia, Perugia, Italy uropg@unipg.it

Carlo Trombetta, MD

Member of ESUI-EAU - Department of Urology, University of Trieste,

Trieste, Italy

trombcar@units.it 